Article

\title{
Psycho-Social Issues in Mine Emergencies: The Impact on the Individual, the Organization and the Community
}

\author{
Kathleen M. Kowalski-Trakofler * and Charles Vaught \\ Retired Office of Mine Safety and Health Research, National Institute for Occupational Safety and \\ Health, Pittsburgh, PA 15236, USA; E-mail: ktrakofler@gmail.com
}

* Author to whom correspondence should be addressed; E-Mail: ktrakofler@gmail.com; Tel.: +1-412-835-7740; Fax: +1-412-833-0106.

Received: 12 April 2012; in revised form: 15 May 2012 / Accepted: 17 May 2012 /

Published: 11 June 2012

\begin{abstract}
This paper draws on research conducted in the past two decades examining issues related to the human element in mine disasters. While much of the emergency response community employs a systems approach that takes into account psychosocial issues as they impact all aspects of an emergency, the mining industry has lagged behind in integrating this critical element. It is only within the past few years that behavioral interventions have begun to be seen as a part of disaster readiness and resiliency in the industry. The authors discuss the potential applications of psychosocial studies and suggest ways to improve mine emergency planning, psychological support, and decision-making during a response, as well as actions in the aftermath of incidents. Topics covered, among others, include an economic rationale for including such studies in planning a mine emergency response, sociological issues as they impact such things as leadership and rescue team dynamics, and psychological issues that have an effect on individual capacity to function under stress such as during escape, in refuge alternatives, and in body recovery. This information is intended to influence the mine emergency escape curriculum and impact actions and decision-making during and after a mine emergency. The ultimate goal is to mitigate the trauma experienced by individuals, the organization, and the community.
\end{abstract}

Keywords: underground coal mine; disaster behavior; judgment and decision-making; emergency expectations training; mine emergency response 


\section{Introduction: Framing the Issue}

Research over the past twenty years has investigated a major over-arching theme in disasters: the role of human behavior and the psychological issues present during and after a disaster. There has been extensive research on behavior and the psychological impact of disasters, both man-made (terrorism, technological) and natural (hurricanes, earthquakes, floods, tornados, etc.). Research in this area began more than 30 years ago with Russell R. Dynes and Enrico Quarantelli at the University of Delaware [1,2] and continued in earnest after the Oklahoma City bombing of the Murrah Federal Building and also the sarin gas release in the subway in Tokyo, Japan in 1995. Human studies on disaster response and interventions have increased exponentially since the unprecedented terror attacks on 11 September 2001. The mining industry is not immune to the human effects of disaster, both natural and man-made.

On 20 November 1968, an event occurred that was to bring a far-reaching change in the regulatory oversight of coal mining in the United States. At approximately 5:30 a.m., an explosion ripped through the Number 9 mine of the Mountaineer Coal Company near Farmington, West Virginia. The blast was felt in Farmington, 12 miles away. Over the next few hours, 21 miners escaped, but 78 did not. Eight of the survivors were on a crew working in a section of the mine called "7 South". On 30 June 2008 one of the crew members gave a first-person account to researchers from NIOSH's Office of Mine Safety and Health Research [3]:

I was on maintenance. I was a mechanic. But, I was running buggy [electric haulage vehicle] extra that night running buggy on 7 South section. And we were in Number 7 heading and I had about a half buggy of coal from the loading machine and the power went off, just "click". Power went off. Everything. So I stepped off the buggy and thought "what in the world is going on?" I stepped back into the intersection and just man, it was like somebody hit me in the face with a bucketful of dirt. Couldn't see. Couldn't breathe. So I pulled my shirt up over my face and just sat down. You couldn't see your hand in front of your face, it was so dusty.

[We all] got back to the dinner hole where the self-rescuers [CO filter devices] were. So we immediately put our self-rescuers on and went down the track heading. Our man-trip [personnel carrier] was blown off the end of the track about four blocks. Trolley wires were blown out of the hangers. Our section [haulage] belt; part of it was turned upside down. There was block stoppings blown in both directions for 200 feet. The explosive force when we got to the crosscut, where the hanging went over to the new airshaft, the roof bolt plates actually turned vertical, from the explosive force. That new airshaft relieved enough pressure off of us that it didn't kill us right where we were. So we went on toward the new airshaft, crossing an overcast that was built to stay there 20 years. It was really double-walled 12 inch block, overcast double walls, 90 pound steel on top on one-foot centers with half-inch plate laid in between the rails and all concreted on top, and it just tore that overcast all to pieces. It twisted rails like a dishrag, broke rails, run rails into the rib. It scattered blocks for three or four hundred feet in both directions. And when we got to that overcast, the section foreman stood on a pile of rubble there, and looked at us and said, "Something awful has happened". And the guy wet his pants. 
Our belt-head man, Paul Henderson, [was missing] and myself and Jerry Davis went back down to the belt-head, which we probably should not have done. Because the only thing we had was little self-rescuers and they're only good for up to two percent carbon monoxide. And our belt-head man's bucket was still sitting at the belt-head, and we looked all up and down the empty loaded track and all around the belt drive and back down the main line for two or three blocks, till I got a very bad feeling that we better not go any further. Apparently, the atmosphere was good enough at the belt head that we didn't get down. It was kind of a foolish move on our part. We might of lost two more men looking for one.

When we got to the bottom of the air shaft, five of the guys that were with us took the self-rescuers out of their mouths. I left my self-rescuer in my mouth, and within 30 minutes, the five guys that had taken the self-rescuers out of their mouths were on the pavement. They were down [Rescuers on the surface] dropped a resuscitator down to us, an oxygen resuscitator. I went over to the five guys that was down and turned the oxygen on and put the mask on their face. Louis Lake seemed to be in the worst condition; the miner operator. And when he started stirring around somewhat, I put a two-hour gas mask on him, and I didn't know at the time, from lack of training, that anybody that's down from carbon monoxide, you do not give him a full shot of pure oxygen all at once, cause it makes him sick. So I looked at the first guy and his face piece was filling up with vomit. And I cleaned his out, and he threw up, I threw up, the next guy threw up; everybody threw up. You know, because, too much oxygen too quick. But at least we got the guys breathing decent and got them covered up with some brattice cloth and got the gas masks on.

[Rescuers on the surface] told us they were in the process of getting a hydra-crane and a muck bucket or a construction bucket to pull us out. And about 9:30, [they] said, "The bucket's here," and they started lowering the bucket down to us. The construction bucket got about 20 feet from the bottom and stopped. And I said, "Let it down about another 20 feet, John." And he said, "We're out of cable". So they had to pull the bucket back up, pull all the cable off the cranes, and send to Fairmont Supply and get all new cable. Bring it from Fairmont to Mannington. Rethread the cable on the crane. Put the bucket on again and then send it down. An odd thing is that they had lowered a two-gallon bucket down to us with a big mayonnaise jar full of hot coffee and wrapped in rags on a 3/8's hemp rope. And the bucket set down, and I pulled the rags off the top and saw the coffee in the jar. And I did not have my gloves on. I went to pull the jar up out of the bucket and the lid was hot. I couldn't handle it with my bare hands; I had to put my gloves back on. So I pulled the jar up out, and I said to Charlie Crim, "Charlie you want some coffee?" He said, "Yep." And that was the only thing Charlie'd said the whole time we were at the bottom of that shaft. And Charlie came over and took the jar and screwed the lid off of it, and turned that coffee jug up, and probably drank three inches of coffee out of it. That was so hot, it was scalding, and it didn't even burn him. Now that's the kind of state of mind you can get in, okay?

They finally sent the bucket down and told us to put in the first three people, the sickest people. I said, "John, that's a pretty good size bucket; we can get more than three people in it." He said, "Well, we don't know what the bucket's gonna do. It might get halfway up 
the shaft and upset; we don't know what it's going to do." I said, "Boy John, you're full of good news this morning, aren't you?" But we put the three sickest people in first and they hoisted them up. And then they sent it back down and we put the next three in and sent them up. And the bucket made the third trip, and Charlie, Bud Hillberry, and I made the third trip. We got 15 feet from the top of the shaft, and the wire rope jumped the shiv-wheel on the end of the crane boom and fouled the cable. And Bud Hillberry said, "Why don't you raise the crane boom up?" It was a hydra-crane, so they did and swung the boom over and got us out.

People just didn't know which direction to go. You know? "Well at least we got you." "Yeah, but there's 78 still in there. How're we going to get them out? Can we get them out?" You know? Rescue teams days later tried to get in, but there was still too much gas and minor explosions going on. I knew then they weren't going to get any more out alive. The lady that lived next door, her son rode to work with me and he had just drawn his first paycheck; Jerry Yennarro. And she came over to the house, and she said, "Are they going to get my son out?" He was with a track crew and I didn't know where the track crew was. And I said, "Yeah, Momma Yennarro, they'll get him." Well they did years later.

The Farmington Number 9 mine was sealed on 30th November 1968. Body recovery operations began in September 1969 and continued for almost ten years until April 1978, when the mine was permanently sealed. Of the 78 men who died, 59 were recovered. Nineteen others remain entombed in the mine. A permanent memorial at the mine site honors those who perished.

The Farmington miners left a legacy. In the aftermath of the disaster, Congress passed the Federal Coal Mine Health and Safety Act of 1969. This legislation has forever changed the way coal is mined in the United States and has paved the way for continuous improvement in mine safety and health.

Forty-two years later, from an article in the Tribune Review 10/31/2010 K Lifetime Section, "Not in Our Lifetime," Coal River Valley, WV by Chris Togneri [4]:

"I am hoping I can get back to normal, but it just seems like I'm getting worse," commented Stanley "Goose” Steward, who escaped from Upper Big Branch in 2010.

Six months after the explosion killed 29 miners in Upper Big Branch, many residents fear they will never fully recover. The miner, quoted above, spends most days sitting in a lawn chair staring at the densely forested mountains surrounding his home. In the cemetery next door lie three of his closest friends, fellow miners who were killed April 5 (2010) at Upper Big Branch mine. (He) used to be an avid hunter, runner and fisherman with many friends. These friends have stopped calling, which is fine with him as he wants people to leave him alone. He finds no enjoyment in anything. "There is something in me, eating me from the inside out, and I don't know what it is, and it won't come out." He will never mine coal again. "The last two or three weeks, I've been worse than I was even right after it happened. I don't know if it's possible I'll ever be normal again."

A miner's wife in the same part of WV noted that "whenever there's an ambulance or a helicopter, the kids are always asking if there was another accident if another miner died. They'll never forget." 
Another miner's wife noted "at the end of the day, the kids know when Daddy's supposed to be home. If Daddy's late, they start to panic."

One miner recalled performing CPR on the first seven miners brought out of the mine after the blast. He said seeing his lifeless brothers, their faces blackened by the blast causes him to look at people and picture how they might look dead. "I can't stop it." he said. He admits that he drinks too much beer, lacks motivation, and gets frustrated easily. He can't sleep without pills, and nightmares interrupt the sleep he gets.

Human psychological and social (psychosocial) issues impact all aspects of a disaster. They involve not only the victims but also the front-line rescuers, all members of the incident command system, and the families and communities - even national and international communities - connected to the events. Further, from a psychological standpoint, a mine disaster does not end when rescue and recovery efforts are complete. The psychological aftermath is often just beginning and has an effect on survivors, as evidenced in the Togneri article and in the Gary Martin interview.

The goal of this article is (1) to provide a background in the human element of disasters and (2) to make recommendations for improving interventions before, during, and after a mining disaster to help mitigate the human psychological consequences.

A survey of the literature was completed to determine which aspects of behavioral research in emergencies were applicable to the mining industry in the United States. In addition to a review of NIOSH studies over the past 20 years, this literature review included an analysis of the 2008 NIOSH international contract reports on escape and rescue from Australia, South Africa, China, Ukraine, Poland, and Russia as well as an academic research contract study completed on the psychological aspects of escape and rescue [5]. In addition, other industry's emergency response programs were examined to determine their applicability to mine emergency response [6]. An independent review of legislation and other reports were also analyzed [7-11].

The paper is organized to (1) define the human element in disasters by examining psychological issues and financial impact (2) discuss the human element including judgment and decision-making under stress, leadership in emergencies, information and communication, expectations training on self-contained self-rescuers (SCSRs) and refuge alternatives, work shifts and fatigue, and rescue team exposures (3) provide recommendations for pre-, during, and post-disaster interventions. Portions of the report are excerpted from the authors' previous publications. When these excerpts are identified, the original document is referenced.

\section{Defining the Issue: The Human Stress Response}

A mine disaster can be one of the most stressful, traumatic events an individual can experience. It can cause both short-term and long-term effects on mental health and functioning. To understand these effects, their impact, and potential interventions to mitigate the effects, it is important to understand the stress response, what a psychological trauma is, and what happens to people during and after a traumatic event.

The oft-called "fight or flight" stress response is a normal, mind-body human response, which was initially studied in the 1920s by Hans Selye [12], an Austrian endocrinologist. Selye postulated that the human organism survives by maintaining a normal internal balance called homeostasis. When a 
physical or psychological threat disrupts homeostasis, it can produce physiological reactions in the body. These physiological reactions involve the nervous and endocrine systems and produce various system and organ responses. Specifically, stress leads to activation of the autonomic nervous system and to an increase or decrease in secretions of hormones such as epinephrine or adrenaline [13]. In fact, stress is a physical body response (Figure 1) that, if continued over an extended period of time, can lead to disease (Figure 2).

Figure 1. Physical reaction to stress.

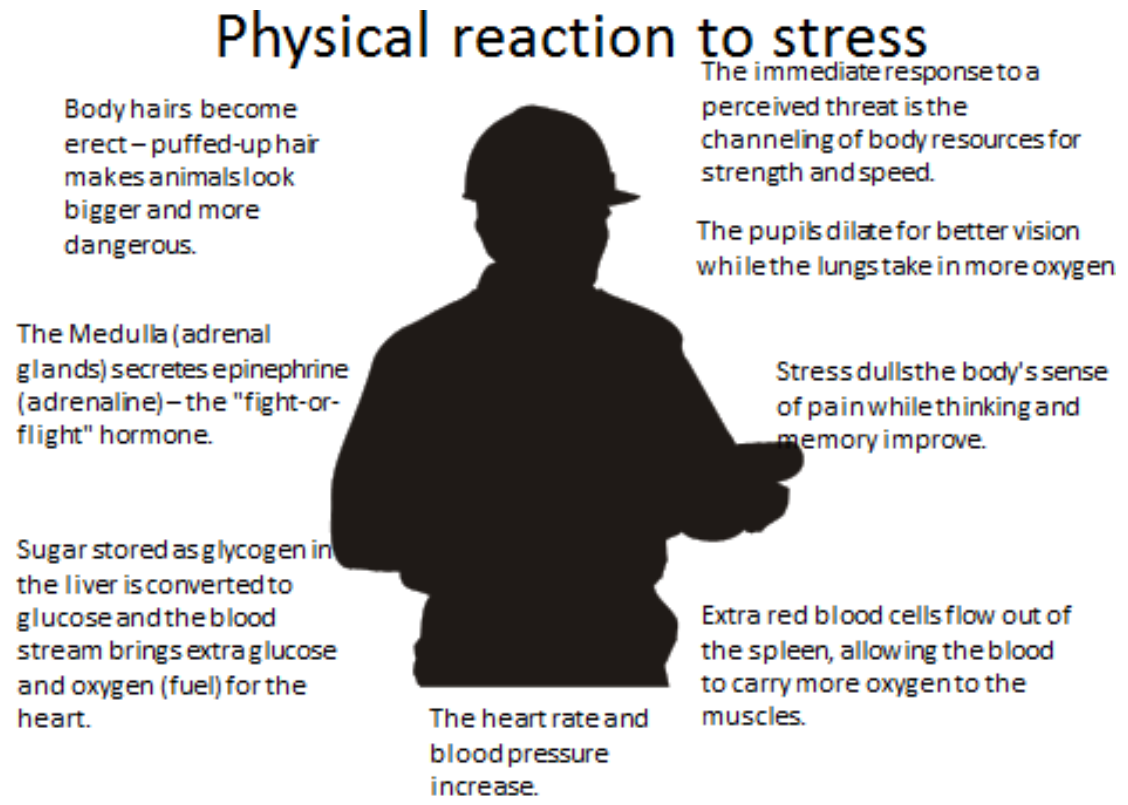

Figure 2. Disease responses to stress.

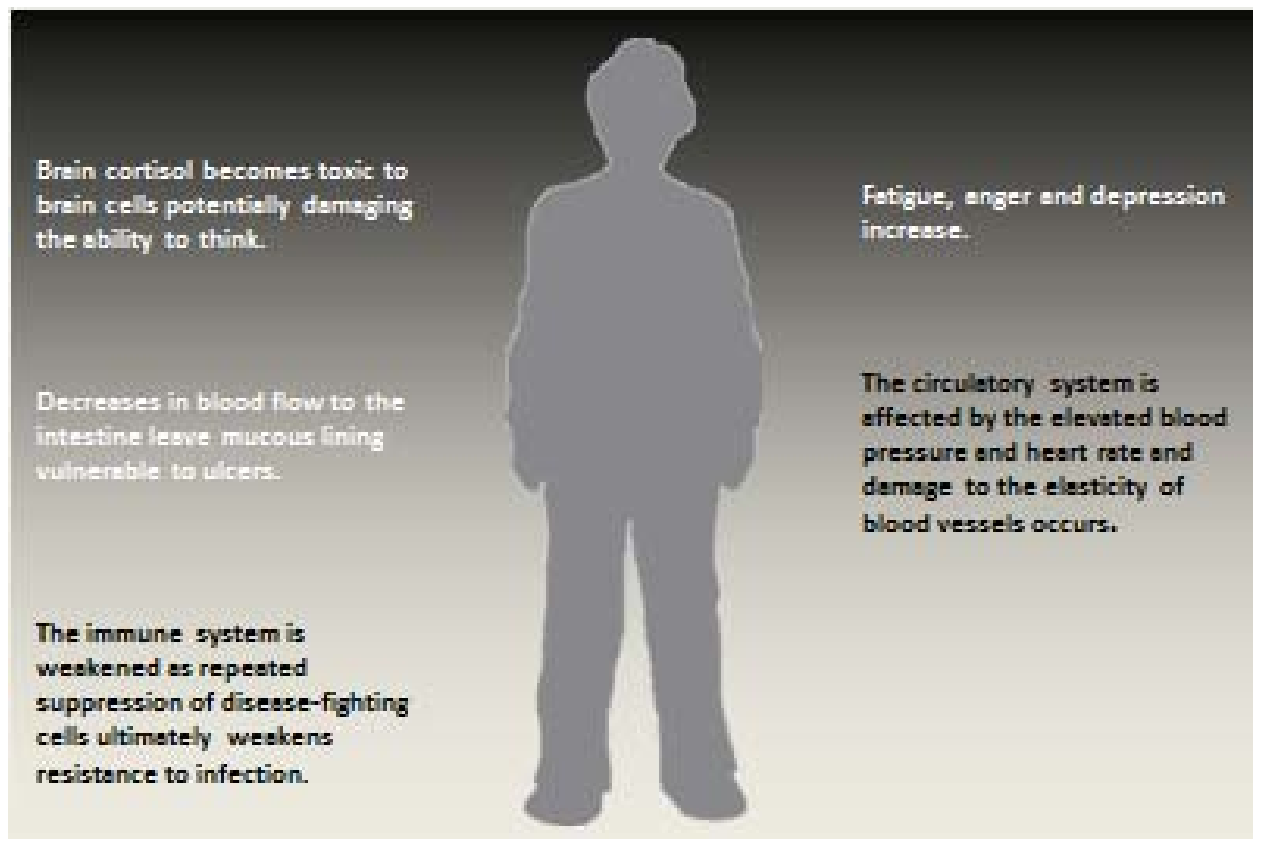

A stressor can be either psychosocial or biogenic. Psychosocial stressors are environmental events wherein the individual's interpretation plays a key role in the onset of the stress response. In other words, one's perception of a situation determines if the stress response is initiated. Thus, a 
circumstance that may be stressful for one person may not be stressful for another person. Typically, there is a range of individual responses to a stressful situation. Further, the onset of the stress response may vary. Some individuals may react to a traumatic incident immediately; others may not react for hours or even days. This is important to understand in a disaster situation. In a mine disaster, one can expect individuals to respond differently according to their interpretation of the danger, including prior experience with similar events.

Biogenic stressors are stimulants, such as caffeine, nicotine, amphetamines, phenylpropanolamine, or theophylline; they initiate the physical stress response directly. Both psychosocial and biogenic stressors initiate the stress response, but psychosocial stressors do not directly cause the stress response; only those psychosocial stressors interpreted as threatening by the individual will initiate the stress response. It is not necessarily what happens to us, it is the meaning we give to the experience that makes the difference. The body does not know the difference between biogenic or psychosocial initiation of the stress response.

Stress may be further categorized as either cumulative stress (i.e., the daily hassles that can add up over time) or acute stress an immediate response with relatively rapid onset. Traumatic stress is an extreme case of an acute stress reaction to a sudden, intense, and unexpected incident. A mine emergency could easily lead to traumatic stress. It should be noted that the stress faced by emergency responders and command center personnel over time could qualify as cumulative stress as they may find themselves in similar stressful situations over and over again. The three incidents in 2006 (Sago, Alma \#1 and KY Darby), followed by Crandall Canyon in 2008 [14,15] and Upper Big Branch in 2010, certainly could qualify as cumulative stress for those personnel responding to two or more of these intense incidents.

When individuals are under duress, their hearts beat faster, and blood is diverted to the skeletal muscles. During stress, an individual may experience shock; temperature, blood pressure and respiration rate remain high; there is a sudden outpouring of adrenaline; the throat becomes dry; digestion stops; and eyesight improves. The body prepares to respond to the danger to be ready to either fight or run away (flight) [16,17].

This response was useful to prehistoric humans in their efforts to survive dangerous animals, human enemies, and other conditions of primitive environments. In today's societies, the dangers may differ but can be equally severe and more complex. Modern humans are besieged with overlapping stressors, and the constant response to them creates wear and tear on the mind and body (cumulative stress). In addition, emergencies and disasters may expose individuals to sudden intense stressors (acute stress). Both types of stress interrupt homeostasis and result not only in physical consequences but also cognitive, emotional, and behavioral consequences for the individual. Short-term symptoms and longer term symptoms can include difficulty concentrating and making decisions, emotional responses such as anger or fear, and behaviors such as acting out or withdrawal. See Figure 3 for a more complete description of potential responses to traumatic stress [18]. 
Figure 3. Potential responses to traumatic stress.

\begin{tabular}{|c|c|}
\hline \multicolumn{2}{|c|}{ Short-term symptoms } \\
\hline Numbness & Denial \\
\hline Avoidance & \multirow{3}{*}{$\begin{array}{l}\text { Difficulty concentrating } \\
\text { Relationship problems }\end{array}$} \\
\hline Withdrawal & \\
\hline Depression & \\
\hline \multicolumn{2}{|c|}{ Long-term symptoms } \\
\hline Fearfulness & Sleep disturbance \\
\hline Flashbacks & Feelings of guilt \\
\hline High anxiety & Irritability \\
\hline
\end{tabular}

Post-Traumatic Stress Disorder (PTSD) is considered to be the most severe and disabling variation of stress. The general public became aware of PTSD following the Vietnam War, when soldiers were reporting symptoms of a duration and intensity that called for medical intervention. In fact, the U.S. Military has long been aware of the traumatic consequences of combat. The term "soldier's heart" came into use following the Civil War. "Shell shock" was the common term from World War I. And from World War II, we have the term "battle fatigue".

PTSD is a medical diagnosis recognized in 1980 by the American Psychiatric Association and described in the 1994 Diagnostic and Statistical Manual of Mental Disorders (DSM IV). It is a psychiatric diagnosis made three months post-incident. Before three months have passed, Acute Anxiety Disorder is usually the diagnosis, though many of the symptoms are similar. Acute anxiety disorder, however, does not necessarily become PTSD. DSM IV is under review; it is likely the definitions will be updated.

Symptoms associated with PTSD include flashbacks or nightmares, reliving of events, exaggerated startle responses, sleep disturbances, detachment or avoidance of close, interpersonal relationships, feelings of guilt, high levels of anxiety and depression, and impairment of concentration and memory. Symptoms may last for a short period of time or for years. Responses can fluctuate and be confusing and disturbing to the individual, his or her family, and co-workers.

The stress response is an appropriate, normal response in an emergency. Unfortunately, a traumatic incident may lead to longer term, ongoing stress responses that can interfere with daily living. In defining the issue, we have focused on individual response to an emergency, but, a disaster can have an impact on many others, including the individual's family, community members, and co-workers.

\section{Human Themes in Disaster}

The experience of human stress is not a new issue. Traumatic stress reactions during war have been reported by historians since $603 \mathrm{BC}$. Thousands of combat stress victims were reported during the American Civil War and among American service personnel in the two World Wars. Police psychologists were added as members of emergency response in the mid-1960s and have made important contributions related to providing psychological support services. Emergency medical service agencies began developing support services in 1972; the first programs were in trauma centers and large hospitals [19]. 
As mentioned earlier, it is only within the last twenty years that research has been undertaken in earnest in the area of human response to disaster. The mining industry has provided only limited empirical data, but other studies on the human element can be applied to the mining industry. An attitude and resource allocation shift in mine emergency response to include the psychological issues pre-, during, and post-disaster must rely on empirical observations from experiences outside the industry.

Researchers from NIOSH and other organizations suggest four human elements or themes of importance to consider in mine disasters, the first of which is human behavior, an element to which the U.S. mining industry has not given enough attention.

For example, after the first underground explosion in the $2001 \mathrm{Jim}$ Walters Resources \#5 mine disaster in Brookwood, Alabama, a number of miners went to the area where they thought their buddies were down, only to be killed in a second explosion. Though their reported motive was to help their downed buddies, their decisions, in retrospect, were based on misinformation or lack of information.

In the 2006 Sago, West Virginia mine disaster, miners made decisions that negatively affected the outcome of their actions. When they started to ride out of the mine and their mantrip hit debris, they initially continued their escape on foot. Upon encountering smoke, they donned their SCSRs. Four members of the group concluded their units were not working and apparently did not "cold start" the apparatuses. That action, combined with the fact that there was smoke in the entries, appears to have convinced the workers that their best course of action was to return to the section and await rescue. This decision may have been influenced by the fact they did not know how far they would have to travel to get to fresh air and by the mistaken belief that rescue would not take much time. Once back on the section, they decided to use curtain material to erect a barricade. Several of the miners removed their mouthpieces. There is a possibility they were unaware that when one stops breathing into this particular unit the chemical bed starts to solidify, making continued use of the device problematic.

In this case, more knowledge or different thinking might have resulted in a different outcome. First, smoke should not be a deterrent to escape, especially when there is limited visibility. Second, there weren't adequate materials to build an effective barricade. Third, a better estimate of how long it would take to sink a bore hole or for a mine rescue team to reach the section might have caused the crew to reconsider the possibility of traveling through smoke. Fourth, greater knowledge about how their SCSRs worked could have given the miners more confidence that they could use them effectively to escape. It is certain that the seeming failure of four units played a role in their decision to return to the section. And, as it turned out, the decision was an unfortunate one.

Studying the human behavior aspects of incidents provides data for prevention, strategies for escape and rescue, information for incident command decision-makers, and skills and interventions for training. Lessons learned from Jim Walters \#5 included the importance of accurate information and communication; lessons from Sago included communication issues and the need for SCSR expectations training [15], which is designed to give miners a feel for what it is like to actually wear the apparatus. A second human element theme in disasters is the issue of communication behavior. Communication was the number one issue mentioned when mine emergency response experts and miners who experienced escape under duress were interviewed concerning the critical first moments of a mine fire [20]. While examples of communication breakdowns were repeatedly noted, the interviewees also agreed that technology was important, as were trust, leadership, pre-planning, and non-verbal communications. Non-verbal communication must be part of an escape strategy until 
SCSRs with communication capabilities are developed. In the 1990's, NIOSH researchers developed the Emergency Communication Triangle, which determined what key information and in what order of importance that information needed to be communicated. "Who, Where and What", means identify yourself first and then indicate where the incident is and what happened. Today's miners could benefit from continued training in this area [21].

The third human element theme is people's reactions once an emergency situation has been identified. NIOSH work confirms other research in the field of emergency response, i.e., most people tend NOT to panic. People also tend to follow their normal behavior even though they do experience the normal stress reaction. The normal stress reaction still can imply that high stress situations may lead to confusion and poor decision-making affecting an escape plan and its execution. In addition, unofficial leaders often emerge during high-stress escape situations. Leadership skills are an important component in escape and rescue and will be discussed later in this paper.

The fourth human element theme studied is the behavior of people once they reach safety. From a psychological perspective, the trauma may be just beginning when individuals reach safety. Interventions after-the-fact are generally addressed in mining with a referral to the local county mental health office. Unfortunately, local, rural mental health facility staff members rarely have training in disaster mental health.

\subsection{Judgment and Decision-Making under Stress, Communication and Information}

International Longwall News-UBB transcripts detail early conflicts [22].

On 11 May 2011, The Mine Safety and Health Administration released 25 of the more than 250 WITNESS interview transcripts from the 2010 Upper Big Branch disaster. They revealed that MSHA mine rescue personnel were at odds with Massey Energy officials within hours of the tragic explosion at the Upper Big Branch mine. The transcripts provide insights into the difficulties with trying to piece together what happened after the explosion. They cover how the mine rescue teams established communications and ultimately recovered the 29 bodies, within nine days of the blast. Notably, the documents revealed that Massey sent two company executives underground-the first personnel underground-after the explosion. These two individuals were underground well before the arrival of MSHA rescue teams.

An MSHA mine rescue team captain, who had more than 12 years of experience with its mine emergency unit, didn't know who these two individuals were when they first encountered them. They quickly had conflicting views over recovery approaches, according to the mine rescue captain's interview transcript.

The mine rescue captain was critical that the company had staff underground at the mine so quickly after the explosion and that so many people were underground. "It's bad enough to try to find 29 people, you don't need to have 40 more to look for," he said. "You don't need to have people run in there. Anybody could've done anything in that mine that they wanted to. They could've controlled, they could've changed controls or anything. We just had a major explosion. "They could've killed every one of us. At that time, we was 
[sic] expendable that night, that's my opinion, at no cost to get to these people. They didn't care what they did with us. That's my opinion."

On the release of the transcripts, assistant secretary of labor for mine safety and health Joseph Main provided context of the difficulties mine rescue personnel can face. "As many mine rescue events of the past have indicated, confusion is not uncommon, and information is not always effectively communicated as rescuers search for survivors in a race against time and in a life-threatening atmosphere," he said. "This rescue operation was no different."

Stress and decision-making are related to information and communication. In studies of escape from underground mine fires, researchers have identified several human behavioral and organizational dimensions relevant to understanding decision-making under duress. First, initial warnings in dangerous situations are often unclear, sometimes due to the way technology behaves and sometimes due to faulty human communication. This can lead to different interpretations of the problem. People also tend to normalize initial warnings, not taking them seriously. Second, people frequently fail to gather the right kinds of information, which prevents them from making appropriate responses. Third, once a decision is made, individuals respond well to a leader. However, if leadership is lacking, people tend to become confused. Finally, apparatuses (e.g., those used in mine emergencies) may not work as expected or may fail. Not only are emergency decision-makers under stress affected by their own stress response and its resulting consequences, the information they must base their judgments on is often unclear, faulty, and incomplete [23].

\subsubsection{Focus of Attention}

Does stress narrow the focus of attention? Do emergency personnel, who are under time constraints and often have limited or unreliable information, become more focused on specific details or do they focus on the "big picture?" Do they become scattered in thought and behavior? The research related to these questions is inconclusive. In several time pressure studies where individuals were given a difficult task to complete in an unreasonable time, subjects tended to become more focused. Negative information became important because it needed to be evaluated and discarded. Stress reduced the tendency to offer solutions before all decision alternatives were considered [24-26].

In other studies involving risk and time pressure, it was found that individuals do not fully explore all information and tend to adopt a simpler mode of information processing. In addition, with risky situations such as in an emergency response, individuals may become more cautious and place importance on avoiding losses [27]. Narrowing the focus of attention and "missing" information was thought to be bad because all alternatives are not considered. But narrowing the focus of attention may be good as it allows the individual to focus just on critical issues and elements, eliminating non-essential information and highlighting the most important sources as a basis for decision-making. Experience may also play a part in the ability to select important information. Whereas a novice will systematically go through all options, an experienced individual may be better able to narrow the options based on previous situations [28].

Decision-making is affected by the uncertainty of the environment. An emergency environment is dynamic and uncertain [29]. Yet, in a dynamic situation, the decision-maker can use feedback on the 
effect of his/her actions quickly and use this information in future decisions. In such a situation, the decision-maker must achieve a trade-off between the cost of action and the risk of non-action. In a lab study, under high levels of pressure, participants tended to wait until a situation was deteriorating before acting. Participants tended to choose further information over action, even as the situation was clearly falling apart [30].

\subsubsection{Analytical vs. Intuitive Judgment under Stress}

It is generally assumed that the best decisions are rational and based on logic and factual information. This assumption has implications for the discussion of judgment and decision-making under stress. Researchers have tended to look at reason and emotion separately. A value has been placed on decisions made with reason: "it is a careless, but common usage to suggest that when we make bad decisions, they are based on emotion, but when we arrive at good decisions, they are based solely on reason" [31].

Different situations demand different kinds of thinking. Some situations call for increased analytical thinking, and others call for increased reliance on intuition. Both the environmental conditions and people's reactions to them are keys as we look at judgment and decision-making under stress. The following case studies are examples of decision makers' following different paths but achieving successful outcomes. Hammond [24] describes the following:

Case 1: The USS Samuel B. Roberts, operating in the Persian Gulf, struck a mine, caught fire, and began to sink. The Roberts' captain, Commander P. X. Rinn, drawing upon his training and experience, analyzed the situation and determined a course of action directly opposed to Navy protocol. From his knowledge of how much water the ship could take on and still stay afloat, Rinn realized that the Roberts would sink before his crew could extinguish the fire. Commander Rinn made the decision to focus on keeping the ship afloat and give the fire second priority. He is on record as having arrived at his decision analytically, based on available information, training, and operational experience.

Case 2: A United DC-10, on its way from Denver to Chicago, lost its hydraulic fluid and, hence, its controllability. Captain Al Hayes and his crew had to discover an alternative way to fly the plane by using the throttles, something their training had not prepared them for, and they had to do it with few of the cues usually available to pilots. That they were able to land with minimal loss of life may be attributed to intuitive decision-making under stress.

The two cases presented portray decision making in life-threatening circumstances under two distinct scenarios: one where the knowledge and training of the decision maker were readily applicable and one where the decision makers' training had not prepared him or his crew for the situation they faced. Both instances involved individuals who were highly trained. In many dynamic settings, such as mining, those who are forced to make initial decisions in emergency situations have some training but limited experience in emergencies. This is because in a mine incident, it may take substantial time to bring experienced command personnel and emergency response teams to the site. 
Considering the issue of analytical vs. intuitive judgment, a NIOSH report observed that research focusing on judgment must include scrutiny not only of decisions that are made, but also of the real-world situation. The quality of a decision may have little or no direct relationship to the eventual outcome in a given situation. This is because a decision-maker is constrained not only by the stress of the situation, his/her personal knowledge, training and attitudes, but also because he or she can only weigh information that is available [23].

Decision-making by response teams in the field and their interaction with command have been examined. Greek researchers Kontogiannis and Kossiavelou [32] studied the decision-making strategies and cooperation patterns used by proven, efficient teams in adapting their behavior to cope with stressful emergencies. The authors concluded that stress restricts cue sampling (focus), decreases vigilance, reduces the capacity of working memory, causes premature closure in evaluating alternative options, and results in task shedding.

A study of military commanders found that teams with records of superior performance have one common critical characteristic: they are extremely adaptive to varying demands [33]. The teams in this study could maintain performance using just one-third of the time usually available to make decisions, but the mode of communication changed. Initially, the team responded to explicit (direct) requests from commanders. As time pressure increased, they stopped waiting for explicit requests and instead provided commanders with information they implicitly (indirectly and unspoken) determined would be useful. Serfaty and Entin [33] suggest that changes from "explicit" to "implicit" communication can help teams maintain performance under time pressure.

The authors conclude that effective changes in communication patterns may involve updating team members regularly, anticipating the needs of others by offering unrequested information, minimizing interruptions, and articulating plans at a high level in order to allow flexibility in the role of front-line emergency responders. The authors found support for the main hypothesis that team coordination strategies will evolve from explicit coordination under low workload conditions to implicit coordination as workload increases.

High reliability organizations, such as those on aircraft carriers and at nuclear plants, exhibit a similar flexibility. They operate under conditions of extreme hazard with little latitude for failure. Organizational structures, functions, and a safety climate that promotes rapid and effective communication are critical to maintaining safe work practices [34,35].

What factors influence a person's ability to make good decisions during an emergency? There is limited agreement on how to define those factors. Real-world, high-risk occasions and emergency situations such as those discussed above create the need to better understand judgment and decision-making under stress. The fundamental assumption is that, while there are untold successes, there are also notable failures resulting from decisions that can be ascribed to one or more errors of judgment. What part, then, does stress play in the commission of these errors? This is a question for further inquiry. A seasoned mine emergency manager noted during a NIOSH interview that sometimes a good decision does not lead to a successful resolution of the problem. On the other hand, sometimes poor decision-making still results in a successful resolution [20].

So, what is the advice for the emergency manager, mine operator, command center personnel, or mine rescue personnel based on the data? Unfortunately, the authors cannot offer a "list" of factors to consider in judgment and decision-making under stress. The present, limited data do not support such 
an approach. There are serious limitations to generalizing from laboratory studies to real-life emergencies. We know that there is an interaction: stress affects human decision-making. What we do not know is the exact nature of this interaction. We can, however, make some observations.

- The research suggests that successful teams communicate amongst themselves, are flexible and, as the emergency intensifies, develop a "flatter" communication hierarchy with more (unsolicited) information relayed from the field to the command center. Command center personnel can facilitate and encourage this type of information.

- Stress is affected by perception; it is the perceived experience of stress that an individual reacts to. However, extremely hazardous emergency environments will create some degree of stress reaction in every worker present.

- A common approach by emergency managers in public safety response (firefighters, police, EMTs) is to minimize stress for the responders through pre-event training.

- Contrary to popular opinion, judgment is not always compromised under stress. Some studies show that the individual adopts a simpler mode of information processing that may help in focusing on critical issues.

- Decisions can only be made based on the information available, and studies have shown that on many occasions decisions are made with incomplete information. Action vs. the consequences of no action must be taken into consideration.

- More recently, decision-making support systems are being developed and incorporated into response. These programs should be tested under conditions of stress (time pressure is one option) to evaluate their effectiveness. Only systems that have replicated stress conditions in the field should be considered for use in mine emergency response.

\subsection{Expectations}

The very understanding of stress as having an interpretive component supports the need for expectations training to mitigate potential negative cognitive and behavioral reactions such as anxiety, confusion, fear, difficulty making decisions, sleep disturbance, depression, PTSD, or compassion fatigue (which may develop by helping or rescuing victims.)

\subsubsection{Self-Contained Self-Rescuers}

After the Sago mine disaster in 2006, where 12 miners lost their lives, investigators and researchers were quick to analyze the root cause of the explosion without trying to understand the behavior of the miners who decided to barricade and to take off and/or share their self-contained self-rescuers (SCSR). The sole survivor reported that four of the units did not work; yet, NIOSH tests indicated the SCSRs had not been used to capacity. NIOSH completed one study after Sago to determine realistic miner expectations while donning and wearing these units and determined nine key areas representing issues that might influence a miner to remove his/her breathing apparatus: (1) starting the unit, (2) unit heat, (3) induction of coughing, (4) unit taste, (5) difficulty in breathing while wearing the unit, (6) quality of the air supplied, (7) nose clips, (8) goggles, and (9) the behavior of the breathing bag [36]. 
This study resulted in a NIOSH training program on expectations that became part of the Mine Safety and Health Administration's (MSHA) mandated SCSR switchover training six months after the Sago disaster. During this work, NIOSH researchers developed a definition for expectations training as "training that provides the trainees with sufficient physical, cognitive, psychological, and behavioral information (beyond the necessary technical information and hands-on experience) to allow them to understand any potential symptoms they might experience while performing a task or action" [36].

\subsubsection{Refuge Alternatives}

The introduction of refuge alternatives into underground coal mines in 2009 has created important psychological considerations for the safety and health of the mining population. Effective 2 March 2009, the MSHA final rule on Refuge Alternatives specified that there must be refuge alternatives in underground coal mines and annual "expectations training" on them [75.1504(c) (3)] [37]. The potential psychological impact of confinement in refuge alternatives is an important consideration for the physical and mental well-being of trapped miners.

The use of these alternatives has raised a number of psycho-social questions, beginning with when, and if, to go into a chamber. Escape is always the first option in a mine emergency. NIOSH has developed two training programs, Harry's Hard Choices, which focuses on decision-making, and a second program focusing on what a miner might expect from a psychological perspective in a refuge alternative [38,39].

NIOSH initiated a project to "develop engineering guidelines associated with the location, construction, and general application of various refuge alternatives" [40]. The first phase of the project evaluated the impact that refuge alternatives could have made in the outcome in coal mine explosions, fire emergencies, and mine inundations in which fatalities occurred from 1970 through 2006. The potential effect of refuge alternatives on both survivors and fatalities was estimated. Thirty-eight disasters were studied, and the results indicated that the availability of "refuge stations" (alternatives) would have had a positive impact on the outcomes of 12 disasters ( 32 percent) of those disasters. The total number of miners who would have been positively impacted was 83 (19 percent) of the 429 underground and impacted (miners) by these accidents. "A total of 74 (29 percent) of the 252 fatalities would have been positively impacted and potentially would have survived the accident. These numbers are based on the assumptions that were made during the analysis of the mine disaster reports. These assumptions are conservative and based on sound understanding of coal mining environments, operations and procedures" [40]. The report also specified that psychological factors would strongly influence miners when using a refuge chamber [41].

The research on the psychological aspects of confinement in a refuge alternative is very limited. It is possible, however, to extrapolate and apply to mining research in other areas such as the military and studies with confined spaces and extended time in confinement.

A hot, humid, closed, and cramped refuge alternative environment is likely to be uncomfortable and to tax coping strategies. Over time, miners are likely to feel crowded, sleep-deprived, irritable, bored, and restless. Other noxious stimuli could include loss of privacy while toileting, odors emanating from the chemical toilet and from other occupants, and the absence or presence of noise by machinery or life support systems. Low level or lack of lighting can compromise the body's natural circadian rhythms. 
Muscle cramps and joint pain from physical positioning during confinement (sitting, recumbent) and/or other discomforts depending on the refuge alternative's design are also possible.

In addition to the challenges mentioned above, there is a risk of triggering unresolved traumatic memories in individuals with a prior history of traumatic exposures (including a mine disaster, explosion/fire, vehicular crash, assault, or military combat). Reviews of fallout shelter studies, underwater habitability studies, NASA manned spaceflight human factors research, mine disaster field studies, and other sensory deprivation and confinement studies has led to the prediction of likely psychological reactions, including anxiety, withdrawal, apathy, aggression, hostility, depression, and irrational and impulsive behavior. Visual illusions and hallucinations were reported in mine disaster field studies in which trapped miners were subjected to prolonged periods of darkness (1-2 weeks) and uncontrolled hazards (roof falls).

Researchers noted a shift in the behavioral dynamics of trapped miners in two case studies reviewed, finding that, initially, miners were very focused on the task of escaping and then became more concerned with survival for themselves and their group, which turned the focus to individual emotions and working toward group cohesion. Miners were likely to be confused and disoriented upon entry into the refuge alternative, and consequently were very anxious, mainly due to the effect of the disaster. Specific psychosocial and environmental factors noted to cause significant stress included a lack of outside communication, prolonged darkness (sensory deprivation), the presence of injured miners, and the experience of powerlessness to provide appropriate medical assistance.

If miners elect to stay in a refuge alternative, it is important that they believe it is the last alternative and have confidence someone will rescue them. Present mine rescue practice in the United States has not been changed to accommodate large numbers of trapped miners, nor has a protocol been developed to rescue miners in a refuge alternative.

In South African mines, strata chambers are used as refuge alternatives because their flat-lying shallow seams allow large diameter drills to drill through the earth and rescue miners. Strata chambers are constructed in one location in a mined opening and isolated from the mine atmosphere with airlock seals. A drill and escape capsule were successfully used at Quecreek in 2002 where nine miners were trapped after machinery broke through into an abandoned, adjacent mine and an inundation of water flooded the working mine. Alternatively, most U.S. underground mines have more limited access pathways than were available for the Quecreek rescue. This conclusion derives from a NIOSH evaluation of surface seismic array sites at three mines that had disasters [42]. Mine rescue teams must be prepared to enter the mine through the existing portals to assist miners who choose to remain in alternatives.

For people who are directly exposed to a disaster, acute post-traumatic reactions are not unusual and tend to emerge early on as acute anxiety. These reactions can include hyper-vigilance, difficulty sleeping and nightmares, feelings of anxiety, event-specific fears, anger or rage, and vulnerability. In a review and study of behavior associated with underground coal mine fires, NIOSH researchers found similar response symptoms. Recovery can be rapid for most, slower for others, and for some, may not occur at all.

Many disaster research studies have observed non-specific indicators of distress or perceived stress. The ability to "think forward" in such a situation may help increase miners' ability to cope with a situation of confinement in a refuge alternative. Thinking forward includes talking about "what's next", 
scheduling communications with significant others, developing a routine, and, in general, focusing on the immediate future.

In 2010 there was a massive roof collapse in a Chilean gold and copper mine. Thirty-three miners were trapped. The miners were not discovered for 17 days, and it was initially estimated that it could take up to four months to rescue them from the mine. Although in a limited and defined space, the Chilean miners were not restricted to a refuge chamber and could move around upright. Once discovered, the miners were provided with light. The ability to control light and darkness is important for physical and psychological health.

According to the London Times, the Chilean Health Minister said that some of the men reported having difficulty sleeping at night and were becoming increasingly anxious and irritable after being cramped in a confined space for so long. The Health Minister indicated that anti-depressants and other drugs were lowered to the men to address these and other issues [43].

At one point a camera was lowered and a "tour" of the cramped underground space was done by one of the miners who illuminated the area with his cap lamp. He showed how the miners had organized their space, creating a medical supply corner, a meeting and planning area, and areas for sleeping, praying, and playing.

The fact that the miners were able to communicate, and even use humor, with rescuers and family members played a role in their mental health in much the same way as social support systems contribute to wellness and recovery after illness or death of a loved one. Strong leadership was also a significant factor in coping with the situation as evidenced in the group's organization throughout the ordeal [43].

Miners are trained to work together and take care of each others' well-being in the hazardous mining workplace. Mining communities are known to pull together to and support one another through difficult days and times. The Chilean incident was a successful example of what is possible when miners, families, and local and global communities work together to provide suggestions, materials, encouragement and support.

\subsection{Leadership}

Leadership is a key factor in mine escapes and rescue activities. The following story supports the need for attention to this issue:

A small village in Lassing, Austria-population 2000-became famous after a tragic mining accident in July, 1998. At a depth of 60 meters (approximately 200 feet) underground, water and mud broke into a shaft of the mine in Lassing. What is left in memory from this incident ten years later is the huge hole in the earth that swallowed up several houses, the mine workers who survived for 10 days, who could not be reached and remain buried in the mine, the rescue leader declaring the death of all mine workers prior to the rescue of the one survivor and the chaos that prevailed for one week.

Lassing became a synonym for crisis mis-management. Initial leadership was lacking and the most crucial after-the-fact finding was that most mistakes were caused by selfish fights over which group would be the lead agency. A positive amongst the chaos was the precision of the drilling teams and it was concluded that better leadership would not have 
made a difference in rescuing the 10 miners who perished. Yet, the lack of a clear leadership structure in a crisis can be catastrophic [44].

Individuals seek out leaders when in crisis. The qualities individuals most often seek in a leader are competence and benevolence [45]. Thus, it seems that leaders exert much of their effectiveness by allaying fears and providing hope for those who follow them. Kolditz and Brazil [46], in their review of leadership in high risk and life and death situations concluded that "authentic" leadership was most valuable. Authentic leaders are confident, optimistic leaders who possess high moral character and ethical reasoning. Authentic leaders are most likely to create loyalty, obedience, admiration, and respect. These leaders lead by giving purpose and motivation and by providing direction in extreme conditions. In the final analysis, leadership resides with those who follow. While the leader may have the vision and courage to lead, it is those who follow who must recognize those qualities. It is those who follow who must perceive the leader as someone who can be trusted and someone who possesses strength and competence to successfully lead those who follow to safety. NIOSH research on leadership supports a number of these findings [45].

In March 1988 a major fire occurred in an underground coal mine in western Pennsylvania, followed by two more such incidents at other local mines. All three incidents forced the evacuation of miners who were working beyond the area of the fire and had to escape through smoke-filled passages in a very hostile environment. Forty-eight miners from eight groups of escaping miners were interviewed by NIOSH researchers about their escape experiences.

To examine leadership characteristics, data were separated into eight separate escape groups and coded according to (1) evidence of leadership behavior, (2) evidence of lack of leadership behavior, and (3) characteristics of the individual in each group who led the miners out of the mine safely. In some cases, the hierarchal leader (foreman, mine inspector, supervisor) led the group out of the mine. Some groups experienced an apparent breakdown of leadership during their escape, while others witnessed the emergence of non-hierarchical leaders. One of the study's conclusions was that the day-to-day production boss is not always the appropriate emergency leader.

The mine escape leadership study identified six characteristics of the leaders. First, the leaders were all adept at incidental learning - they were attentive to the environment and noticed things others did not. Second, the leaders developed naturally during the course of the escape decision-making. No one "seized" power. Third, the leaders were decisive yet flexible in that they were willing to adjust their decisions with new information. Fourth, they listened to input from others. Fifth, the leaders were aware of the fear in the group and exerted a calming influence. Sixth, the leaders used a logical/analytical decision-making process.

The study provided support for the affiliative model of emergency response where everyone stays together in escape, as opposed to the panic model where it is every man for him or herself. In other words, the majority of miners behaved appropriately within the accepted social framework of behavior for the situation. Effective leadership increased the likelihood of efficient evacuation [45].

Leadership, the qualities of leadership, and the effectiveness of leadership principles are also evident at the organizational level. The effectiveness of a particular crisis or disaster intervention and subsequent psychological recovery often relies on the organizational leadership behind the response itself. These authors and others [47] suggest that, on a grand scale, the disaster response to Hurricane 
Katrina stands as a tragic reminder of the consequences of failed leadership and failed coordination of services. The Sago mine disaster stands as an example of poorly coordinated public information services when all miners were reported alive when indeed they were not (only one survivor). The need for a competent leader for an organized and highly coordinated disaster response is an important consideration when developing disaster response plans, executing those plans during an actual disaster, and evaluating lessons learned post-incident.

The actions of the leaders during the Lassing, Austria mine disaster are particularly pertinent to this paper. Quickly recognizing the need for psychological support for victims and others, the Lassing leaders called in a psychologist and two social workers, none of whom were trained to provide psychological support during disasters. Specially trained police psychologists were then called but were overwhelmed by people's needs for support. Finally, professionally trained disaster mental health teams were called. The Lassing study supports the need for specially trained counselors in disaster mental health to be available, which supports the need for pre-planning. This is discussed further in the Mental Health and Intervention sections.

A problem noted by mine emergency response experts in the United States in "A Study of First Moments in Underground Mine Emergency Response" and affirmed in 2008 discussions with mine rescue personnel, was concern with the present cumbersome U.S. mine emergency command center dynamics [20]. Personnel represented in a mine emergency command center include representatives from management who are mandated to be in charge, federal and state authorities who have responsibilities and can negate mine management's decisions and, if a union mine, a representative from the United Mine Workers of America (UMWA). The individuals in the mine emergency command center historically are well-versed in mine technology but not in employing the standardized National Incident Management System (NIMS) for emergency incident command or unified command. The mining industry employs its own Mine Incident Command Center (MICC) protocols [48].

\subsection{Work Shifts and Fatigue}

In response to mine disasters, mine rescue teams and Mine Incident Command Center personnel work long hours. A 2006 NIOSH report reviewing the growing body of research on long work hours indicated that long work hours can have serious health and safety consequences $[49,50]$, such as injuries, cardiovascular disorders, stress, musculoskeletal discomfort, work-family conflict, increase in risky behaviors and motor vehicle crashes, medical errors, and loss of productivity. Most studies on longer work hours have been conducted with specific occupational groups such as nurses or construction workers; the data collected may not necessarily generalize to the overall workforce, emergency personnel, or mining in particular.

There may be additional adverse effects associated with 12-hour shifts and heavy workloads, as would be the case in an emergency operations center. The long shifts and lack of sleep were associated with diminished alertness and performance [51,52]. These effects could apply to overtime work as well [53].

In a unique study on the quantification of impairment induced by fatigue, researchers compared the effects of sustained wakefulness and alcohol intoxication. After approximately 20 to 25 hours of wakefulness, subjects performed at a level equivalent to those with a blood alcohol concentration 
(BAC) of 0.10 percent. Overall, these results suggest that moderate levels of continued wakefulness produce degradations in performance equivalent to or greater than those observed at levels of alcohol intoxication that are unacceptable when driving, working, and/or operating dangerous equipment [54].

In the stress associated with a disaster, incident command, rescue, and recovery personnel often report that they "run on adrenalin" [20]. Fatigue is not something on which there are data, but anecdotal evidence suggests that fatigue is rarely considered in mine emergency preparedness, planning, and response. Nevertheless, fatigue is an important issue, especially in the incident command center, and can be a serious deterrent to effective rescue and recovery operations. In their review of decision-making in emergencies, Kowalski-Trakofler et al. [28] noted that "a flatter communication hierarchy develops with more (unsolicited) information coming from the field to the command center". This promotes a condition wherein the command center may be overwhelmed with information, which dilutes the ability to discern relevant from irrelevant information.

Findings such as these would suggest that extended work shifts in the MICC during disaster operations may contribute to a decline in cognitive abilities. The implications for such a phenomenon would be an increased potential for impaired decision-making, poor communication, and compromised interactions with the media, the public, families, and others as shifts are extended during rescue and recovery operations. Such conclusions suggest that operations throughout the MICC should be closely monitored from a psychological perspective, and shift rotations should be planned so as to sustain the highest possible levels of collective cognitive performance. Generally, an ideal shift might be nine hours with eight hours on duty and one hour of overlap for communicating with the relief person before and after shift. Rotating shifts should not be included in pre-disaster planning. Where rotating shifts become unavoidable, in order to accommodate one's circadian rhythms the direction of rotation should be forward (i.e., morning to afternoon to night), never backward [51].

Circadian rhythm is a daily cycle of biological activity based on a 24-hour period and influenced by regular variations in the environment, such as night and day. People's highest level of activity usually happens in late afternoon or early evening when the body's ability to produce energy from food (metabolism) is also at its highest. The least activity usually is in the middle of the night when most people are asleep. There are also personal differences in circadian rhythms. People perform best when alertness and internal body activity is high and worst when alertness and activity are low. One can conclude from this information that during extended periods of darkness when a person's Circadian rhythms are disrupted safety behavior can be compromised.

\subsection{Rescue Team Exposures and Dynamics}

From USA Today, Crandall Canyon, UT [55]:

A cave-in killed three miners and injured six other men who were tunneling through a coal mine trying to reach six miners trapped for 11 days. Distraught family members of workmen, some of them children, arrived at the mine entrance looking for news. They hugged each other and cried. (The) Huntington Mayor told MSNBC the town was "devastated by the turn of events. We all feel like family when one hurts."

(Two of the deceased in the cave-in were mine rescue personnel.) 
By definition, a traumatizing event is one that is outside the normal range of everyday life events. It is experienced by the individual as devastating. An example of a potential traumatic incident for a miner would be the serious injury or death of a co-worker. Traumatizing events are more frequent among emergency workers such as mine rescue teams, command personnel, and state and federal mine officials. These events can result in an emotional reaction with the potential for inhibiting a worker's ability to function either at the scene or at a later time. Another example may be in body recovery where distressing circumstances, sights, sounds, and smells result in immediate or delayed stress reactions. Of interest to this discussion is the fact that of the five senses, smell lasts longest in memory. Even many years after a disaster a smell can trigger a flashback. The smell of smoke, for example, can trigger a flashback for a coal miner who escaped from a mine fire. Visual memories can also trigger flashbacks.

The field of disaster mental health has developed as the research on trauma and behavior in disasters has grown. Although researchers and psychologists who specialize in job stress generally agree that persons attracted to emergency work are, as a group, basically more emotionally stable than the general population, emergency workers are subject to an increased incidence of stress-related diseases [56,57]. Post trauma reactions are natural, though not necessarily healthy responses to trauma, and they can usually be resolved. There is consensus among clinicians and researchers that the presence of a supportive environment is crucial to a positive resolution for the traumatized worker [58]. Successful resolution of the crisis experience not only allows for the worker's return to productive work but can help him or her better understand a normal response to an atypical situation. As noted, empirical investigations of the effects of crisis and disaster on personnel, organizations, families, and communities have increased in the past 20 years. Previous studies have documented the nature of the human stress response and the short-term and long-term consequences of exposure to a disaster [59]. For the most part, emergency workers have learned to deal with traumatic events and take them in their stride. However, there are certain circumstances when rescuers experience an emotional reaction to an emergency situation. They may develop an emotional connection to the victim or the victim's family, in which case the rescuers have reported increased symptoms of traumatic stress.

This is relevant in rural mining communities where "everyone knows everyone". Disaster workers who reported identifying with the deceased as a friend were more likely than those who did not identify with the deceased to develop PTSD, have intrusive thoughts, and experience avoidance behaviors [60]. The RAND/NIOSH report after 9/11 found that personal and professional bonds led to greater risk-taking [61], including those exposed vicariously or second-hand [62-64]. Compassion fatigue is also an issue for responders who may over-empathize with victims and families.

It is important to note that not all response to rescue and recovery work is negative. The members of the military assigned to recover bodies in the 1985 incident in Gander, Newfoundland, to be discussed in the next section, reported pride in their contribution and indicated they would volunteer for the job again. A study of recovery workers after the 2010 earthquake in Haiti indicated a similar finding [65]. Generally, most people do quite well following exposure to trauma. 


\subsubsection{Body Recovery}

In a mining disaster, the removal of bodies from the mine may be necessary. Exposure to multiple deaths as well as individual dead bodies can be stressful, disturbing, and even frightening. Bodies may be burned or dismembered, or they may be intact - which has its own emotional consequences. Responders after the Gander, Newfoundland plane crash of 1985, which killed all those aboard, reported that natural looking bodies with no apparent cause of death were disturbing.

The task of body recovery after a mine disaster may be prolonged as in the case of the 2010 Upper Big Branch mine disaster in West Virginia where 29 miners died. As the deceased were discovered in the mine, it was necessary for the mine rescue team to continue searching for potential survivors. Ultimately, there were no survivors, and recovery of the bodies began after a number of days, exposing the mine rescue team to a difficult and prolonged exposure to the dead miners' bodies. The discovery and removal of the bodies after the 2006 Sago disaster was also challenging for the mine rescue personnel.

Responses from exposure to the dead after a traumatic incident are not well understood. Although it is recognized that exposure to dead bodies is one of the major stressors in disasters, limited research has been completed on the psychological effects on rescuers [60]. Ursano [60] noted that major psychiatric textbooks do not even mention the topic. Some researchers hold that regardless of previous experience, exposure to violent death can create additional victims in those who assist after the disaster [59]. In addition, miners who witness or arrive on scene shortly after an incident are affected. The authors suggest that anecdotal evidence from mining industry personnel confirms that even experienced miners and mine rescue personnel can suffer psychological effects from exposure to dead bodies.

Mine rescue personnel have reported to the authors that waiting time, i.e., the anticipation of when they will enter the mine and begin their task, is most difficult and stressful. The safety of the mine rescue team is top priority, which may mean building additional roof support or stoppings, removing debris, and constant gas monitoring before the team can move forward in search of potential victims. Sometimes teams are pulled out of the mine for a situation to be reassessed. This can be frustrating and stressful for responders. Studies of first responders, such as firefighters, support the view that the stress of anticipation has important psychological and physiological effects [66,67].

The limited studies in this area have resulted in some observations. Previous experience with a stressful event may reduce the effects of the present stressful event. Ursano [66] conducted a study in 1985 with the military responders after the Newfoundland crash. He found that inexperienced individuals report higher levels of fear and anxiety than do experienced individuals. A significant stressor in body handling is the sensory stimulation. The smell, the visual presentation, and the tactile sensation are often reported. Some have recommended that a masking smell be used such as a gel scent rubbed under the nose. Unfortunately this may create other problems later, as that smell will be associated with the experience and create memories and distress.

The sight of a large number of bodies at the Newfoundland crash was described by some as "overwhelming." One rescuer indicated that it felt like "you were surrounded" [66]. Surprise, shock, and fear of the unexpected are disturbing aspects of handling dead bodies. Also, identification with or emotional involvement with the deceased produces a high degree of distress. This can be a major issue 
in small and close-knit mining communities when rescuers may know the victims or their families. The common reaction of "it could have been me" is particularly potent in a rural mining community.

Again referring to the Newfoundland crash, researchers commented that grief and emotional upset were not often observed on the site itself as people are concerned about their public image and how they might look in front of peers, supervisors and subordinates. In response to questions posed to rescuers at the Newfoundland site, such as: "What if leaders are not able to be macho that day? Do you lose faith in them?" The answer from an experienced team leader was:

No, no, no! You can't lose faith in them. You have to talk to them and let them talk to you.

"What was it that bothered you on that case?" Tell them that it's OK to get sick or say

"Hey! I can't deal with it today." 'Because their psyche won't allow them to deal with that body that day, we can't think any less of them because tomorrow it might be our turn.

Unfortunately, that is not always the present attitude, especially in the military and in a male-dominated, volatile, dynamic industry such as mining.

Humor is recognized as a tension reducer during and after operations and is more common when workers are out of public view. Most humor by the Newfoundland response team was reported to be respectful rather than "black" humor. For most, professional counseling, if available, was viewed as unacceptable. The reasons included fear of job loss and peer ridicule. Interestingly, almost all of the responders said they did not feel the need for counseling but that they could have benefited from a brief talk about the experience with the work group, though some wished these meetings had been mandatory. The [66] report continued that:

Spouses of the body handlers were frequently unwilling to hear about the workers' experience; other times, the workers themselves decided not to talk to their spouses about the disasters. One man reported that his wife required him to take his clothes off at the door and shower after any contact with remains. Others described their first (and sometimes only) attempt at telling their spouses how they felt about their work and reported that they were unlikely to repeat the experience.

The return to work was difficult for many, especially when coworkers were not sympathetic or sensitive. Most workers appreciated some time off after the job was over. The general feeling was that those who had not been at the site could not understand what the volunteer had gone through. This made it more difficult to talk about their experiences. Coping mechanisms vary after a traumatic event involving fatalities [68]. Reports after the 1995 Oklahoma bombing and the terrorist attacks on 9/11 have supported an increase in alcohol use by responders [69]. Management of dead bodies is often based on the false belief that they represent an epidemic or disease hazard if not buried or cremated immediately. Though human remains may contain blood-borne viruses such as hepatitis B and C and HIV as well as bacteria that cause diarrheal diseases, they pose no risk to someone walking nearby, nor do they cause significant environmental contamination. More accurate information may reduce anxiety for rescue workers [70].

There are recommended precautions for workers who handle human remains, including (1) protecting the face from splashes of body fluids and fecal material; (2) protecting the hands from direct contact; (3) maintaining hand hygiene; (4) providing prompt care-cleansing and get a tetanus 
booster for any wounds sustained during work; and (5) participating in available psychological and emotional support programs for workers. It is important that body bags be used. The sight and smell of decay are unpleasant and can be disturbing, but they do not create a health hazard [71].

In most jurisdictions in the United States it is the county coroner's job to pronounce someone dead. In a mining incident, a coroner or his/her deputy may or may not choose to go underground. Michael A. Baker, County of Indiana, PA Coroner, in a presentation to the Pennsylvania Governor's Families First Response and Communication Advisory Council in April 2011 provided guidance in this area. He noted that how the families are notified of their loved one's death and how they are supported is the most important activity in a disaster. He also provided specific suggestions for mine operators. He said, do not:

1. Move the body (except for imminent danger to the life or health of rescuers or survivors);

2. Rock dust (unless there is imminent danger of an explosion), which can cover up evidence

3. Move machinery (unless necessary for safety);

4. Cover the body if there has been a crime; the coroner recommends that the body not be covered as evidence may be compromised. There is usually not a crime in a mine accident, so covering the body is acceptable;

5. Permit access of unauthorized personnel to the area;

6. Attempt to notify the family (until after the coroner's pronouncement, and with the coroner's involvement).

Only the coroner may authorize removal of the body and is responsible for notification, although these responsibilities may be delegated. In addition, before an announcement to the news media, family members must be given time to notify other family and close friends. Baker's research indicates that family members remember if the notification is too public. He cited an example of an official's coming to the family member's workplace and taking them into the hallway. Family members remember if inexperienced personnel were sent for the notification without enough information, such as: "where is the body now?" Families need an answer to "what happens now?".

In certain cases, a mine has to be closed when it is too dangerous to enter and remove the deceased. Such was the case in the 2008 Crandall Canyon, UT disaster and in the 2010 BP Deepwater Horizon explosion in the Gulf of Mexico. In both cases, the bodies were never recovered. This increases the trauma for family, friends, and co-workers. Every effort should be made to identify bodies, and mass burial should be avoided if at all possible. Families need the opportunity to conduct culturally appropriate funerals and burial according to social custom.

\subsection{Mental Health Issues}

From The Associated Press [72]:

Two miners whose jobs included watching over safety at the Sago Mine before the deadly explosion in January 2006 "committed suicide" in September of that year, approximately eight months after the explosion and death of 12 fellow miners. Neither man had been blamed for the disaster that killed 12 of their comrades, nor did either one's family 
definitively link the suicides to the accident. But those who knew the men say there is little doubt the tragedy haunted them.

"I'm not sure anybody ever gets over it," said the ex-wife of one of them. "You live with it every day." One of the men had retired shortly after the explosion and the other a week before his suicide.

The Sunday 8 October 2006 edition of the Pittsburgh Post-Gazette included an article from writer Chico Harlan, who wrote about one of the Sago suicides. In an article titled "Sago Mine: shredded skin, scarred psyches for disaster survivors," he wrote that the week before, a sign in the Sago bathhouse, posted shortly after one of the suicides, directed the miners to a group counseling session where they could talk about the trauma they had all survived but rarely acknowledged. The subject of the article had agreed to the session as he recognized that his job underground had felt joyless since mid-March when the mine reopened-plus it allowed him to cut a few hours from his workday. He walked daily through the Second Left section, where, on 2 January an explosion trapped 13 men, killing 12 of them. "I think about it every time I'm there." After the accident, most people talked about the one survivor, but there were 29 men who had been underground. A few weeks before, one of the miners had found a half-piece of a deceased miner's hard hat, ripped apart by the force. "Sixteen men escaped, all they got were scars." In the session, according to Harlan, one of the men stated, "Your nerves stay shot. Every single noise, you jump. You're on edge all the time. Counseling-I went once." They told me this and that, but I said "Just leave me alone. It don't help you any. You just go on living if you want to live." "I wanted to get away from it all, but I can't", another miner said, "Too many memories. It brings tears to your eyes."

\subsubsection{Background}

There are five generally recognized psychological phases of disaster:

1. Initial impact phase;

2. Heroic phase where people are helping each other and perform heroic behaviors usually before professional rescue personnel arrive on scene;

3. Honeymoon phase where people are thankful they are alive and thankful to rescue personnel;

4. Disillusionment phase where people begin to get frustrated and angry that things are not happening fast enough (the clean-up, return to homes, help, housing, decent food, etc.). They may feel helpless;

5. Reconstruction phase where people have accepted the new order of things and are rebuilding.

These phases are not linear and people/organizations fluctuate between them. It is not a step-by-step process. Psychological Response stages include:

1. Shock and disbelief;

2. Strong emotional reaction;

3. Acceptance;

4. Recovery. 
Some individuals never move beyond stage 2 or 3 to recovery. It impacts and changes their lives such that they cannot integrate the experience and move on to a "new normal". Again, these are not linear stages, and some people never get to the latter phases or may move back and forth between stages.

The Centers for Disease Control and Prevention (CDC) has developed The Impact Pyramid to illustrate the impact of a disaster on various populations. The top of the pyramid is the victims, followed by family and social networks, rescue workers, medical care providers, their families, and social networks, vulnerable populations and impacted businesses (such as a rural economy with the closing of a mine and the impact on the mining company). At the base of the pyramid are ordinary people and their communities.

No one who experiences a disaster is untouched by it. Strong evidence suggests that disasters lead to psychological problems such as depression, alcohol abuse, and an increase in domestic violence. Physical illness and additional psychological symptoms have also been reported after a disaster [16,73-77].

Suicides and depression may be the result of inadequate psychological support during and after an emergency response. It has been suggested that the most vulnerable time emotionally is from six months to one year after the event. There is increased fear of rages, self-destructive behavior and even suicide. "The despair, the helplessness gets so intense, it bursts out" [78]. There were suicides in the aftermath of both the 2002 Quecreek and 2006 Sago events. Two West Virginia miners who were at the site of the Sago Mine disaster committed suicide within about six months of the event as described at the beginning of this section. Neither man was blamed in the tragedy nor was it clear why either committed suicide. However, family members claimed that these men were continually bothered by the event. Another suicide victim was the man who pinpointed the location to drill at Quecreek, but it is not clear if this played a role in his suicide. These cases support the need for specially-trained counselors in disaster mental health.

\subsubsection{Specialized Training}

Specialized training in crisis intervention may virtually double the clinical effectiveness of mental health interventions [79]. It is no longer appropriate to assume that simply because one possesses a license for the independent practice of mental health that one is competent in this highly specialized area [57]. In some communities, the local Red Cross is available to provide qualified disaster mental health support but is not present for follow-up. Mental health interventions may mitigate serious emotional, behavioral, physical, and cognitive consequences to individuals experiencing a trauma [80]. Rescue workers, incident command personnel, co-workers, and family members are also subject to the psychological after-effects of a traumatic incident.

How long these reactions last is an important concern for crisis intervention programs, but knowledge about duration depends upon the research studies investigating the many consequences of disaster. Longitudinal studies are relatively rare, although they have increased since 9/11. Conducting research under crisis conditions is difficult. Pre-disaster baseline data is practically impossible to obtain. Thus, a direct causal link between disasters and mental health consequences is difficult to determine. Disaster researchers often appreciate the value of crisis situations as a window through 
which the psychological aspects of survival may be observed. Both positive and negative extremes of human behavior occur in a crisis.

Preparing miners, management, and mine rescue teams on what they may normally expect behaviorally, cognitively, emotionally, and physically from themselves and others during an emergency response may have a stabilizing effect on the rescue or recovery. Present thinking in the mining industry is beginning to recognize and support after-the-disaster mental health interventions. Experience indicates that information and services would be beneficial before (planning), during (on-scene), and after a mine disaster.

Effective response to the psychological needs of people after a disaster depends on advance planning. Without planning, questions that could have been anticipated and answered before the crisis must be answered in the midst of the crisis. Who should respond? What training do they need, and how do they fit into the incident command structure? Who coordinates and oversees the support? Unfortunately, groups seldom look at the psychological consequences of a disaster as a critical part of preparedness. The goal is to provide qualified people in a timely manner with appropriate psychological services.

In 1992, the American Red Cross, which responds to disasters small and large, fully implemented its Disaster Mental Health Services Program [81]. This program trains licensed mental health professionals to extend disaster mental health services on site to Red Cross workers and primary victims and is designed to work closely with local mental health agencies. The program was updated and revised in 2006.

One of the most significant impediments to organized disaster response in the public sector has been the changing nature of the public mental health system. Community mental health centers, the frontline of federal and state mental health services initiated during the 1960s and 1970s, are disappearing. In rural mining communities, the local mental health facility is usually the only provider of psychological services. Today, the public mental health system is largely oriented to serving people with severe and persistent mental illness. As a result, public community mental health agencies, which remain the primary sponsors of crisis-counseling programs, are sometimes in a difficult position because of a lack of training, experience, and skills related to providing broad-based services to otherwise "healthy" individuals after a crisis.

Effective mental health services dealing with disasters are different from traditional mental health services in some important ways, including the people served and how the service is provided. Most disaster survivors have never received mental health services and do not see themselves as needing counseling or psychotherapy treatment. There still exists a stigma of mental illness in society. Most disaster survivors are normal people who need to cope with an abnormal or extra-ordinary experience. It then becomes critical that a psychological diagnosis not be assigned indiscriminately or prematurely to individuals experiencing normal responses to a trauma. The federal disaster mental health program is based on a crisis-counseling model and designed to provide short-term intervention. Unfortunately, as mentioned, most rural public mental health facilities do not have personnel trained in crisis intervention.

Following a disaster, people tend to turn to their traditional sources of support such as family, friends, church, and primary care physicians. These organizations and individuals play key roles and can help in providing information and appropriate intervention. It is also important to remember that 
those close to a victim of a disaster may be secondary victims and may experience additional disaster-related problems.

Individuals who have experienced trauma tend to respond to very direct care giving, such as concrete suggestions on managing stress and how to respond to family or organize priorities immediately after the event. By and large, mental health professionals are trained in nondirective techniques in working with patients, specifically techniques that focus on reflection and are more passive. These types of techniques work less well in crisis counseling and again point to the difference between traditional counseling and crisis intervention. The history of federally-funded crisis counseling indicates that effective crisis counselors do not necessarily require the background or credentials of a licensed mental health professional but they do require training in disaster mental health theory, crisis counseling techniques, and screening. Most importantly, it is recommended that they be supervised by licensed professionals who have specialized in disaster mental health and who have a referral system for individuals who may require extended treatment.

\subsection{Other Relevant Studies}

Increasingly, behavioral health is part of planning and response in the nation's emergency response system at organizations such as the Federal Emergency Management Agency (FEMA), CDC, the Department of Homeland Security (DHS), and international agencies. The Inter-Agency Standing Committee (IASC) was established in 1992 in response to the United Nations General Assembly Resolution 46/182. The IASC is the primary mechanism for international inter-agency coordination of humanitarian assistance, and in 2008 published Guidelines for Mental Health and Psychosocial Support in Emergency Settings (IASC 2008).

Many studies on the psychological aftermath of a disaster make use of PTSD, discussed earlier, as a measure of trauma with observable physical, emotional, behavioral, and cognitive symptoms. In an interesting study after a magnitude 7.5 earthquake in Pakistan in 2006, 75 survivors were interviewed. The authors explored the relationship between certain traumatic stressors and PTSD. The findings suggested that being trapped under rubble is a significant predictor of later disorders. Another investigation in 2006 examined the relationship between trauma and "earth fall" mining accidents [82]. The subjects were classified into two groups - a PTSD group and a non-PTSD group. All people in both groups reported feeling as if their lives were in danger; previous trauma was listed as a significant factor in the PTSD group. The authors theorized that being trapped and immobile in complete or near complete darkness was particularly predictive because the situation involved all the senses, i.e., feeling the rocks on the body, tasting and smelling the dust, hearing the rocks and cries of others. The more senses involved in the trauma, the higher the likelihood of developing symptoms. The relationship could be generalized to being trapped under a mine roof fall.

After 2006, NIOSH investigated mine emergency escape and rescue, utilizing in-house researchers, and explored academic and international sources to determine best practices [83-87]. The reports from South Africa, China, Poland, Ukraine, and Russia produced under contract for NIOSH offered little in the way of further information on psychosocial knowledge applied to mine emergencies.

The Australian report, on the other hand, offered an empirically-based behavioral intervention that has been in practice for a number of years - that of self-escape. This intervention provides an 
opportunity for a paradigm shift and behavior change in mine escape for all miners. This is different from the present emphasis in the U.S. on rescue teams to an emphasis on training everyone on many of the skills associated with escape and rescue. Self-escape interventions emphasize a change in thinking, attitude, and behavior in mine emergency response for the United States.

In a mine emergency, self-escape emphasizes the skills of the individual miner(s), their decision-making skills, and group dynamics. Instead of focusing on highly trained mine rescue teams, the focus is on providing each miner with sophisticated training, strategies, and practice in escape. This philosophy fits in with the inclusion of psychological expectations training for miners. Learning what behaviors they can expect from themselves and others could enhance self-escape.

South Africa has a trauma management program called COPE, which was developed by the employee assistance program at the Chamber of Mines to respond to mining workplace accidents. The guiding principles of the program include the belief that psychological trauma should be given the same consideration as physical trauma. Further, the program must be voluntary and confidential such that participation cannot affect promotion potential. The program also provides supervisor training to help identify potential post-traumatic stress disorder (PTSD) cases, based on changes in work performance. The program identifies three levels of intervention: (1) individual major incident, (2) individual minor incident and (3) widespread incident. Each of these types has an associated methodology [88].

The Russian Red Cross initiated a psychosocial support program for the families of miners affected by a blast in two Russian coal mines. They discovered that there were factors unique to people affected by mine accidents. They found that mine accidents have greater effect on everyday life because mines continue to be operational after the incident. In addition, some miners who survived the accident often could not go back to work. Moreover, the families of miners who returned to work constantly worried about their loved ones' lives [89].

Two of the underground coal producing countries studied, as well as one country from additional research, have either acknowledged and/or developed programs to address some of the psychosocial issues of a mine disaster. Analysis of the present status of programs in the industry, reflected by this research and research from the broader emergency response community, indicates that the dissemination of behavioral health information is definitely limited and not well represented in training and policies in the U.S. mining industry. That is not to say that there are not several mine operators in the U.S. who recognize the importance of this issue and have attempted to address it. There is not, however, a specific, consistent program integrating the psychological aspect of disasters into mine emergency response.

\section{Resilience}

Humans are efficient survival machines, individually and in groups. Survival is accomplished not by brute strength or avoidance, but by recognizing and solving problems that provide the ability to cope in a potentially hostile environment. Today's terminology sometimes refers to this construct as resilience - the ability of an individual or organization to both withstand significant adversity and to rebuild after a trauma. Resilience has been described as a dynamic process of healthy adaptation in adversity. Resilience is multi-dimensional and involves personal, organizational, and environmental 
factors, including hardiness, flexibility, and optimism, as well as the availability of social resources, a sense of connectedness and support, and overall intelligence [90]. Resilience is emerging as an umbrella concept for positive behavioral emergency response, with promising identifiable factors that are applicable to improved emergency escape and response strategies. In other words, once identified, these factors can be taught [91].

Developing resilience in the mining population is a pro-active step to improving successful escape, rescue, and command center decision-making. Helping miners develop a healthy adaptation to adversity is central when integrating self-escape behaviors into a systems approach to mine escape and rescue. Although resilience has been defined in many ways [92-96], an on-going NIOSH study has defined resilience as the psychological and social characteristics of an individual miner and mine crew that help them to withstand significant adversity and to "bounce back" after a trauma. The authors of Strategies for Escape and Rescue from Underground Coal Mines [87] concluded that developing resilient miners, who are able to respond and self-escape if necessary, is needed to improve emergency response in the U.S. underground coal industry.

This concept of resilience may be extended to include families, organizations, communities, and nations in their response to adversity. It appears that the single most powerful factor in promoting resilience is the expectation and provision of interpersonal support. The mining industry is described as a community, a brotherhood. Teaching resilience could strengthen the support for individuals within the community. Determining the components of resilience in self-escape from an underground mine, for example, could provide miners with invaluable information in the event of an incident where they must evacuate a mine.

Technology may also play a useful role in resiliency. Under a grant from Microsoft, two professors have been working to create a "Survivor Buddy" in response to the psychological strain that confinement can place on persons. The "Survivor Buddy" robot will be an emergency companion for people stuck in the crossfire of snipers, in mines, or under the rubble of an earthquake-ravaged building. It is expected that the robot will play soothing music to trapped victims and feature a screen showing the faces of loves one and rescuers trying to reach them. It will also deliver water and transmit victims' vital signs [97].

\section{Interventions}

\subsection{Systems Approach}

A disaster response systems approach incorporates the basic hierarchy model of safety. First, engineering controls are employed. The mining industry is heavily focused on eliminating hazards from the workplace, an approach evidenced in disaster response by continual improvements in the technology, Personal Protective Equipment (PPE), and equipment used by mine workers and mine rescue personnel. This approach led to dramatic decreases in injuries and fatalities in the first half of the 20th century in the United States. Next, administrative controls are employed, such as training, scheduling worker shifts to optimize production and safety, providing safety incentives, and influencing management to support a culture of safety to prevent injuries. Finally, attention to 
behavioral interventions contributes to the safety system, including fostering worker responsibility, co-worker support, and attitudes for safe behavior and accountability [98].

Attention to behavioral interventions for mine safety is presently increasing in the mining industry, and awareness of the human element is increasing in mine disaster escape and response.

\subsection{Present Status}

The Mine Safety and Health Administration (MSHA), in response to the 2006 MINER ACT, is working toward incorporating the National Transportation Safety Board (NTSB) response for transportation disasters to mine families after a mining incident. The efficacy of the NTSB program for mining has not been empirically validated. There are a number of immediate issues needing evaluation before such a program is implemented, including a review of the IASC international guidelines and the behavioral disaster mental health programs recommended by the U.S. Departments of Health and Human Services (DHHS), Homeland Security (DHS), and the American Red Cross. The NTSB responds to major incidents such as plane crashes, train wrecks, etc. where victims are unrelated, family members are geographically separate and the incident is considered over within days or weeks.

Mining incidents take place in rural communities where many people know each other, their families, and the mine managers; the effect on the community is typically long term. National experts in DHHS and the Red Cross have suggested utilizing Psychological First Aid, a program providing professional support and training the community to help each other. This is an excellent place to start in providing adequate behavioral health intervention to today's mining community.

After the 2002 Quecreek, PA mine inundation, the Commonwealth of Pennsylvania passed legislation in 2007 to ensure that mine families would be treated with dignity and care in the event of a mine incident. The Mine Families First Act, House Bill \#483, provides for policies and an advisory council to ensure proper protocols are in place.

The Commonwealth of Pennsylvania Governor's Mine Families First Response and Communication Advisory Council, working with the Bureau of Deep Mine Safety, developed an emergency response plan and protocols that can serve as a model for taking care of families during a mining incident where miners are trapped, injured, or awaiting rescue. Key components include specific suggestions for mine operators, family liaisons, and communications. The mine operator continues to have the primary responsibility to the miners and their families affected by an emergency. Although this role has not changed, the Mine Families First Act places the mine operator as well as other support organizations in a more collaborative relationship with families. It has raised awareness of the issue and allowed operators to pre-plan responses and incorporate them into their overall emergency response plan. The state plan identifies specific resources and support personnel for the operators in every county [99].

\subsection{Training}

NIOSH Researchers have explored the issues of traumatic incident stress, burnout, and stress related to training during a simulated escape through smoke, in addition to studying behaviors in underground mine fires $[23,46,100,101]$. In one study, small groups of miners were required to don self-contained self-rescuers (breathing apparatuses), enter an area of an underground limestone mine 
that had been filled with non-toxic theatrical smoke, and travel approximately 885 feet to a door through which they exit into fresh air. Individual subjects immediately provided a self-report of their experiences on questionnaires. The general finding was that miners who had more experience or training also tended to report less stress during the exercise. Studies of emergency responders in public service support the finding that training and experience can mitigate the intensity of the stress response for individuals. These results also support the need for expectations training.

\section{The Bottom Line}

Major disasters can be not only traumatic and stressful, but also expensive for the company, community, family and friends of the victims. In economically uncertain times, a mine disaster can financially impact a company through the need to supply equipment, supplies, and emergency response service personnel. The loss of production and workers can also add financial burdens [102]. The psychological reaction from a major mine disaster affects other employees, work teams, and organizational divisions [103]. Psychological reactions to disasters and the resulting symptoms may cause absenteeism, lost workdays, decreased worker effectiveness, reduced work productivity, increased safety issues, and increased sick leave and mental health problems.

In a study by $\mathrm{Hu} \&$ Slaysman [103] it was found that respondents indicated having difficulty staying focused, and some reported working at a slower pace as a result of exposure to trauma. The American Institute of Stress estimates that stress, and the problems associated with it, cost organizations more than $\$ 300$ billion a year [104]. These costs can also extend beyond the organization into the community. Major disasters have the ability to change the economic conditions of families and possibly increase the health care required for the injured or stressed worker, his/her family, and co-workers. In addition, this may affect the economic and social outcomes and behaviors for other family members, including children. This effect is particularly relevant in the mining industry where the mine is the area's chief employer.

It is not easy to study the psychological and economic effects of a disaster immediately after an event. Consequently, past incidents offer the best information. An early example of disaster consequences was seen in the Three Mile Island nuclear accident. Researchers studying the accident, which occurred on 28 March 1979 near Harrisburg, Pennsylvania, found that inside the 15-mile radius around the accident site, residents were 20 percent more likely to have behavioral symptoms, such as stress, sleep disorders, and anxiety than those beyond the 15 mile radius.

Twenty-two years later, research supported this finding on the effect of proximity to an incident. The proximity to the World Trade Center on 9/11 was positively correlated with increased mental health problems [105].

While direct costs of absenteeism, burnout, and mental health problems can be extensive, they only represent about one-third of the total costs, with indirect costs contributing to the remaining two-thirds. An accepted rule of thumb is that for every $\$ 1$ of direct costs an estimated \$3- \$5 of indirect costs are also acquired [106-108]. In addition to standard losses, such as lost wages and health care costs, there are numerous direct and indirect costs associated with workplace injuries that are often not taken into account when assessing the consequences associated with a disaster. 
Indirect costs include additional hiring, creating programs to retain employees, and loss of productivity due to time delays brought on by the disaster itself. The effects of workplace injury, exposure, or fatality on the productivity of coworkers who may be having difficulty coping, as well as the addition of anxiety because of the potential heightened risk that workers may experience, are also factors. Major disasters like the Three Mile Island example have the ability to impact stress levels, which in turn can influence the demand for health care services and changes in consumption of alcohol, cigarettes, and over-the counter-anesthetics [103]. Studies after both the Oklahoma bombing in 1995 and the 9/11 incidents indicated increased use of alcohol as a coping behavior [104].

There are several costs that are a direct result of absenteeism or loss of an employee. These costs include salary paid to absent personnel. Paid leave is one of the most expensive employer-provided benefits. The time spent by supervisors seeking replacement workers or training new personnel can be significant. There are also overhead costs that can be associated with employees' absenteeism or loss. If an employee is lost due to the psychological or physical effects of a disaster, replacing him/her may not eliminate the negative consequences of the event. Employee work efficiency is often linked with familiarity and practice. Replacement employees often lack the familiarity with the organization and, in most cases, lack the years of experience of those they replace. The costs attributable to re-staffing after the impact of disasters can be substantial [107].

\section{Specific Recommendations for Pre-, During, and Post-Disaster Interventions}

The behavioral health needs of the mining community pre-, during, and post-event are not being addressed adequately. Information from behavior research in emergency response, including the concept of worker resilience, is not reaching the mining industry. Both research and actual experience in emergencies point to the idea that behavioral health should be part of a systems approach to pre-, during, and post-disaster planning and response. Training and appropriate interventions can decrease exposure to the risk and/or increase the number of protective factors. Research in this area has shown that such interventions may mitigate serious emotional, behavioral, physical, and cognitive consequences for personnel [109].

Pre-event

1. Recognize that there are human factors that impact workers in a mine emergency, including escaping miners, mine rescue personnel, incident command personnel, and federal, state, union, and company decision-makers. Recognize the financial impact to the company and to the mining industry.

2. Integrate expectations training into the Emergency Response curriculum. This should include what to expect from wearing an SCSR, normal individual and group behavioral responses to escape, leadership, and refuge chamber expectations. Normal stress response, interventions, and follow-up should be part of the pre-event training. Expectations training should include a thorough examination of the issue of self-escape, personal responsibility, and decision-making. How self-escape changes present mine rescue protocol and how it applies to mining in the U.S. needs serious discussion. 
3. Renew focus on communication, both technical and interpersonal, in reporting information and decision-making under duress. This includes training miners on decision-making and how to report an incident to the outside (Who, Where, What).

4. Develop a relationship with local disaster mental health professionals. Quiz local mental health professionals on their training in crisis intervention and disaster mental health. Grief counseling is not the same as disaster mental health counseling. If local professionals are either not available or are not certified in Disaster Mental Health, contact the Red Cross, the Salvation Army, or other state-related disaster mental health support organization.

During the event

5. Mitigate stress for workers during an event with strict shift schedules, adequate nutrition, hydration, and rest. Avoid overuse of caffeine, a biogenic stressor. Provide diversion for responders if an event continues past two weeks.

6. Provide adequately for family members.

After the event

7. Recognize the need for long-term mental health support by disaster mental health professionals for everyone involved in the emergency. Ease individuals back to work. Be especially alert 6 months to a year after the event for signs of increased mental health symptoms, which could lead to severe mental health issues or even suicide. Immediately refer individuals to mental health personnel.

8. Plan a memorial or other service for families of deceased miners, the community, co-workers, and rescue personnel.

9. Incorporate mental health issues into de-briefing and lessons learned.

10. Be aware that psychological healing takes time.

\section{Acknowledgements}

The authors thank the following individuals for their contributions and support for the body of work represented in this document: Michael J Brnich, Jr., Launa L. Mallett, Robert Peters, Joseph Lybarger, summer intern, Joel Haight all with the National Institute for Occupational Safety and Health's Pittsburgh Research Laboratory. Ted Scharf, Dori Reissman, NIOSH. Joseph Flick, Mark Radomsky, Pennsylvania State University; Joseph Sbaffoni, Commonwealth of Pennsylvania; Jeffrey Kravitz, Joseph Main, Mine Safety and Health Administration; Lynn Rethi, National Personal Protective Technology Laboratory, NIOSH.

This work is dedicated to the mine workers, management, and safety personnel in the mining industry, federal and state government mine personnel, and mine safety trainers, who work every day to keep our nation's miners safe.

\section{Disclaimer}

All web addresses referenced in this document were accessible as of the publication date.

The opinions and recommendations in this paper are solely the authors. 


\section{References}

1. Dynes, R. The Comparative Study of Disaster: A Social Organizational Approach; Disaster Research Center, University of Delaware: Newark, DE, USA, 1975.

2. Quarantelli, E.; Dynes, R. Community Response to Disasters; Disaster Research Center, University of Delaware: Newark, DE, USA, 1985.

3. Martin, G. Escape from Farmington Number 9: An Oral History; National Institute for Occupational Safety and Health: Pittsburgh, PA, USA, 2008.

4. Togneri, C. Not in Our Lifetime; Coal River Valley Tribune Review: Coal River Valley, WV, USA, 31 October 2010.

5. Everly, G.; Perrin, P.; Everly, G. Psychologocal Issues in Escape, Rescue, and Survival in the Wake of Disaster; National Institute for Occupational Safety and Health: Pittsburgh, PA, USA, 2008.

6. Harrald, J.; Fiedrich, F.; Madhukar, A.; Molinia, M. An Annotated Bibliography of Relevant Issues in Human Escape and Rescue Outside the Mining Industry; National Institute for Occupational Safety and Health: Pittsburgh, PA, USA, 2008.

7. United States Congress. Mine Improvement and New Emergency Response Act; United States Congress: Washington, DC, USA, 2006.

8. National Mining Association. Improving Mine Safety Technology and Training: Establishing US Global Leadership; National Mining Association: Washington, DC, USA, 2006; p. 193.

9. Murray, K.; Pogue, C.; Stahlhut, R.; Finnie, M.; Webb, A.; Burk, A.; Beiter, D.; Francart, W.; Tjerlund, D.; Waggett, J. Fatal Underground Coal Mine Fire, Aracoma Alma Mine Number; US Department of Labor: Arlington, VA, USA, 2006.

10. Light, T.; Herndon, R.; Guley, A.; Cook, G.; Odum, M.; Bates, R.; Schroeder, M.; Campbell, C.; Pruitt, M. Fatal Underground Coal Mine Explosion, Darby Number 1 Mine; US Department of Labor: Arlington, VA, USA, 2007.

11. McKinney, R.; Crocco, W.; Stricklin, K.; Murray, K.; Blankenship, S.; Davidson, R.; Urosek, J.; Stephan, C.; Beiter, D. Fatal Underground Explosions, Number 5 Mine; Jim Walters Resources, Inc., US Department of Labor: Arlington, VA, USA, 2001.

12. Selye, H. The Stress of Life; McGraw-Hill: New York, NY, USA, 1956.

13. Asterita, M. The Physiology of Stress; Human Sciences Press: New York, NY, USA, 1985; p. 264.

14. Gates, R.; Phillips, R.; Urosek, J.; Stephan, C.; Stoltz, R.; Swentosky, D.; Harris, G.; O’Donnell, J.; Dresch, R. Fatal Underground Coal Mine Explosion, Sago Mine; US Department of Labor: Arlington, VA, USA, 2006.

15. Gates, R.; Gauna, M.; Morley, T.; O'Donnell, J.; Smith, G.; Watkins, T.; Weaver, C.; Zelanko, J. Fatal Underground Coal Burst Accidents, Crandall Canyon Mine; US Department of Labor: Arlington, VA, USA, 2007.

16. Myers, D. Psychology; Worth Publishers: New York, NY, USA, 1992.

17. Rundell, J.; Ursano, R.; Holloway, H.; Silberman, E. Psychiatric responses to trauma. Hosp. Community Psychiatr. 1986, 40, 68-74. 
18. National Institute for Occupational Safety and Health. Traumatic Incident Stress: Information for Emergency Response Workers; National Institute for Occupational Safety and Health: Pittsburgh, PA, USA, 2002.

19. Mitchell, J. Stress: The history, status, and future of critical incident stress debriefings. JEMS 1988, 46-47, 47-52.

20. Kowalski-Trakofler, K.; Vaught, C.; Brnich, M.; Jansky, J. A study of first moments in underground coal mine emergency response. JHSEM 2010, 7, Article 39.

21. Mallett, L.; Vaught, C.; Brnich, M. The Emergency Communication Triangle; National Institute for Occupational Safety and Health: Pittsburgh, PA, USA, 1999.

22. UBB Transcripts Detail Early Conflicts; International Longwall News: Leederville, WA, Australia, 11 May 2011.

23. Vaught, C.; Brnich, M.; Mallett, L.; Cole, H.; Wiehagen, W.; Conti, R.; Kowalski, K.; Litton, C. Behavioral and Organizational Dimensions of Underground Mine Fires; National Institute for Occupational Safety and Health: Pittsburgh, PA, USA, 2000.

24. Hammond, K. Judgments Under Stress; Oxford University Press: New York, NY, USA, 2000.

25. Gillis, J. Effects of life stress and dysphoria on complex judgments. Psychol. Rep. 1993, 72, $1355-1363$.

26. Keinan, G.; Friedland, N.; Ben-Porath, Y. Decision-making under stress: Scanning of alternatives under physical threat. Acta Psychol. 1987, 64, 219-228.

27. Flanagan, J. The critical incident technique. Psychol. Bull. 1954, 51, 327-358.

28. Kowalski-Trakofler, K.; Vaught, C.; Scharf, T. Judgment and decision-making under stress: An overview for emergency managers. Int. . Emerg. Manag. 2003, 9, 138-143.

29. Scharf, T.; Vaught, C.; Kidd, P.; Steiner, L.; Kowalski, K.; Wiehagen, W.; Rethi, L.; Cole, H. Toward a typology of dynamic work environments. Hum. Ecol. Risk Assess. 2001, 7, 1827-1841.

30. Kerstholt, J. The effect of time pressure on decision-making behavior in a dynamic task environment. Acta Psychol. 1994, 84, 89-104.

31. Lazarus, R.; Lazarus, B. Passion and Reason: Making Sense of our Emotions; Oxford University Press: New York, NY, USA, 1994.

32. Kontogiannis, T.; Kossiavelou, Z. Stress and team performance: Principles and challanges for intellegent decision aids. Saf. Sci. 1999, 33, 103-128.

33. Serfaty, D.; Entin, E. Adaptive team coordination. Hum. Factors 1999, 41, 312-325.

34. Poole, M.; van de ven, A. Handbook of Organizational Change and Innovation; Oxford University Press: New York, NY, USA, 2004; p. 429.

35. Hoffman, J.; Baskaaran, S. The role of visual attention in saccadic eye movements. Percept. Psychophys. 1995, 57, 787-795.

36. Kowalski-Trakofler, K.; Vaught, C.; Brnich, M. Expectations training for miners using self-contained self-rescuers in escapes from underground coal mines. J. Occup. Environ. Hyg. 2008, 5, 671-677.

37. United States Department of Labor. Refuge Alternatives for Underground Coal Mines: Final Rule; US Department of Labor: Arlington, VA, USA, 2008.

38. Vaught, C.; Hall, E.; Klein, K. Harry's Hard Choices; National Institute for Occupational Safety and Health: Pittsburgh, PA, USA, 2009. 
39. Margolis, K.; Kowalski-Trakofler, K.; Kingsley-Westerman, C. Refuge Chamber Expectations Training; National Institute for Occupational Safety and Health: Pittsburgh, PA, USA, 2009.

40. Ounanian, D. Refuge Alternatives in Underground Coal Mines; National Institute for Occupational Safety and Health: Pittsburgh, PA, USA, 2007.

41. Brnich, M.J.; Kowalski-Trakofler, K.M. Underground coal mine disasters 1900-2010: Events, responses, and a look to the future. In Extracting the Science: A Century of Mining Research; Brune, J., Ed; Society for Mining, Metallurgy and Exploration, Inc.: Littleton, CO, USA, 2010.

42. Lowe, N.; Swanson, P.; Varley, F. The Impact of Surface Features above Underground Mines on Emergency Response; Society for Mining, Metallurgy, and Exploration: Littleton, CO, USA, 2009.

43. AOL News; AOL Inc.: New York, NY, USA, 2011. Available online: http://www.aolnews.com/ world/article/trapped-chilean-miners-appear-upbeat-in-video/19610450?icid $=($ accessed on 1 June 2011).

44. Hersche, R.; Wenker, O. Case report: Lassing mining incident. Int. J. Rescue Disaster Med. 2000, 2, 5 .

45. Kowalski, K.; Mallett, L.; Brnich, M. Leadership in Escape from Underground Mine Fires; US Bureau of Mines: Pittsburgh, PA, USA, 1994.

46. Kolditz, T.; Brazil, D. Authentic leadership in extreme settings. MLM 2005, 3, 256-345.

47. Waugh, L.; Streib, G. Collaboration and leadership for effective emergency management. Publ. Admin. Rev. 2006, 66, 131-130.

48. National Mining Association. Mine Rescue Handbook: Emergency Response Procedures, Practices and Responsibilities; National Mining Association: Washington, DC, USA, 2007.

49. Grosch, J.; Caruso, C.; Rosa, R.; Sauter, S. Long hours of work in the US: Associations with demographic and organizational characteristics, psychosocial working conditions, and health. Am. J. Ind. Med. 2006, 49, 943-952.

50. Killgore, W.; Balkin, T.; Wesensten, N. Impaired decision making following $49 \mathrm{~h}$ of sleep deprivation. J. Sleep Res. 2006, 15, 7-13.

51. Caruso, C.; Bushnell, T.; Eggerth, D. Overtime and Extended Work Shifts; National Institute for Occupational Safety and Health: Washington, DC, USA, 2004.

52. Harrison, Y.; Horne, J. The impact of sleep deprivation on decision making: A review. J. Exp. Psychol. Appl. 2000, 6, 236-249.

53. Proctor, S.; White, R.; Robins, T.; Echeverria, D.; Rocskay, A. Effect of overtime work on cognitive functioning in automobile workers. Scand. J. Work Environ. Health 1996, 22, 124-132.

54. Lamond, D.; Dawson, N. Quantifying the performance impairment associated with fatigue. J. Sleep Res. 1999, 8, 255-262.

55. Crandall Canyon, Utah. USA Today. 17 August 2007; Volume 3A.

56. Dunning, C.; Silva, M. Disaster induced trauma in rescue workers. Victimology 1980, 5, 287-297.

57. Everly, G.; Mitchell, J. The prevention of work-related post-traumatic stress: The critical incident stress debriefing process. In Proceedings of the American Psychological Association and National Institute for Occupational Safety and Health, Washington, DC, USA, 19-22 November 1992.

58. Doepel, D. Crisis management: The psychological dimension. Ind. Crisis Q. 1991, 5, 177-188. 
59. Miles, M.; Demi, A.; Mostyyn-Aker, P. Rescue workers' reactions following the hyatt hotel disaster. Death Educ. 1984, 8, 315-331.

60. Ursano, R.; Fullerton, C.; Vance, K.; Kao, T. Post-traumatic stress disorder and identification in disaster workers. Am. J. Psychiatr. 1999, 156, 353-359.

61. Jackson, B.; Baker, J.; Ridgely, M.; Bartisaw, J.; Linn, H. Protecting Emergency Responders: Safety Management in Disaster and Terrorism Response; National Institute for Occupational Safety and Health: Washington, DC, USA, 2002.

62. Fullerton, C.; Ursano, R.; Wang, L. Acute stress disorder, post-traumatic stress disorder and depression in disaster rescue workers. Am. J. Psychiatr. 2004, 161, 1370-1376.

63. Nixon, S.; Bunch, K.; Smith, E. Psychiatric disorders in rescue workers after the oklahoma city bombing. Am. J. Psychiatr. 2002, 159, 857-859.

64. Murphy, S.; Johnson, L.; Beaton, R. Firefighters' Cognitive Appraisals of Job Concerns, Threats to Well-Being and Social Support Before and After the Terrorist Attacks on 11 September 2001; University of Washington: Seattle, WA, USA, 2004.

65. Biggs, Q. Challenges in U.S. Army mortuary affairs remains recovery mission to 2010 Haiti earthquake. In Proceedings of Work, Stress and Health 2011 Symposium, Proceeding of Response and Recovery Work Beyond Familiar Roles: Risk and Resilience Lessons from the Field, Orlando, FL, USA, 19-22 May 2011.

66. Mitchell, J. Stress, the history, status and future of critical incident stress debriefings. J. Emerg. Medical Serv. 1988, 13, 46-47,49-52.

67. McCarrol, J.; Ursano, R.; Wright, K.; Fullerton, C. Handling bodies after violent death: Strategies for coping. Am. J. Orthopsychiatry 1993, 63, 209-214.

68. Hersheiser, M.; Quarantelli, E. The handling of the dead in a disaster. Omega 1976, 7, 195-208.

69. US Department of Justice. Responding to Terrorism Victims: Oklahoma City and Beyond; US Department of Justice: Washington, DC, USA, 2000.

70. Watson, J.; Gayor, M.; Connolly, M. Epidemics after natural disasters. Emerg. Infect. Dis. 2007, $13,1-5$.

71. Morgan, O. The Disaster Impact Pyramid; Centers for Disease Control and Prevention: Atlanta, GA, USA, 2004.

72. 2 Miners Who Watched for Sago Hazards Commit Suicide; Boston Globe Associated Press: Boston, MA, USA, 26 September 2006.

73. Green, B. Psychosocial research in traumatic stress: An update. J. Trauma. Stress 1994, 7, 341-362.

74. Baum, A.; Fleming, I. Implications of psychological research on stress and technological accidents. Am. Psychol. 1993, 48, 665-672.

75. Bravo, M. The physiological effecs of chronic stress at three mile island.1983. J. Consult. 1983, $51,565-572$.

76 Steinglass, P.; Gerrity, E. Natural disaster and post-traumatic stress disorder: Short term versus long term recovery in two disaster-affected communities. J. Appl. Soc. Psychol. 1990, 20, $1746-1765$. 
77. Ursano, R.; McCaughey, A.; Fullerton, C. Individual and Community Responses to Trauma and Disaster: The Structure of Human Chaos; Cambridge University Press: New York, NY, USA, 1994.

78. Lagnado, L. FDNY Tries to Rescue its Own; Wall Street Journal: New York, NY, USA, 2 March 2002; Section D.

79. Stapleton, A.; Lating, J.; Kirkihart, M.; Everly, G. Effects of medical crisis intervention on anxiety, depression, and posttraumatic stress symptoms: A meta analysis. Psychiatr. Q. 2006, 77 , 231-238.

80. Gerrity, E.; Flynn, B. Mental health consequences of disasters. In Handbook of Stress: Theoretical and Clinical Aspects; Goldberger, A., Breznitz S., Eds.; The Free Press: New York, NY, USA, 1998; pp.7-20.

81. American Red Cross. Disaster Mental Health Services Program. Washington, DC, USA, 1991.

82. Stevens, J.; Calitz, J. Trauma-related risk factors in mine workers with PTSD: A prospective follow up study. S. Afr. J. Psychol. 2006, 36, 425-445.

83. Galvin, J. Review of Best Practices for Escape and Rescue from Underground Coal Mines in Australia; National Institute for Occupational Safety and Health: Pittsburgh, PA, USA, 2008.

84. Wu, K.; Gray, T. Review of Best Practices for Escape and Rescue from Underground Coal Mines in China; National Institute for Occupational Safety and Health: Pittsburgh, PA, USA, 2008.

85. Pavlovich, J. Review of Best Practices for Escape and Rescue from Underground Coal Mines in Ukraine, Poland and Russia; National Institute for Occupational Safety and Health: Pittsburgh, PA, USA, 2008.

86. Marx, W.; van Zyl, F.; Doyle, B.; McIntyre, R. Review of Best Practices for Escape and Rescue from Underground Coal Mines in south Africa; National Institute for Occupational Safety and Health: Pittsburgh, PA, USA, 2008.

87. Alexander, D.; Bealko, S.; Brnich, M.; Kowalski-Trakofler, K.; Peters, R. Research Report on Strategies for Escape and Rescue for Underground Coal Mines; National Institute for Occupational Safety and Health: Pittsburgh, PA, USA, 2010.

88. Maiden, R. Managing trauma in the South African mining industry. Int. J. Emerg. Manag. Health 2005, 7, 213-217.

89. International Federation of the Red Cross and Red Crescent Societies. Russian Federation: Mine Blast in Kemerovo Region. DREF Operation Final Report. Geneva, Switzerland, 2008.

90. Reissman, D.; Klomp, R.; Kent, A.; Pfefferbaum, B. Exploring psychological resilience in the face of terrorism. Psychiatr. Ann. 2004, 33, 627-632.

91. Masten, A. Resilience and development: Contributions from the study of children who overcome adversity. Dev. Psychopathol. 1990, 2, 425-444.

92. Rutter, M. Resilience reconsidered: Conceptual considerations, empirical findings and policy implications. In Handbook of Early Childhood Intervention, 2nd ed.; Shonkoff, J., Meisels, S., Eds.; Cambridge University Press: New York, NY, USA, 2000; pp. 651-682.

93. Bonanno, G.; Galea, S.; Bucciareli, A.; Valajov, D. What predicts psychological resilience after a disaster? The role of demographics, resources, and life stress. J. Consult. Psychol. 2007, 75, $671-682$. 
94. Rutter, M. Psychosocial resilence and protective mechanisms. Am. J. Orthopsychiatry 2010, 57, $316-331$.

95. Wolin, S. The Reslient Self: How Survivors of Troubled Families Rise Above Adversity; Villard Books: New York, NY, USA, 1993.

96. Steinberg, A.; Ritzman, R. Resilience and development affective communities. J. Appl. Psychol. 1990, 20, 1746-1765.

97. Colavecchio-VanSickler, S. A USF Professor Plans to Add Heat to Robot Rescuers; St. Petersburg Times: St. Petersburg, FL, USA; 2008.

98. Kowalski-Trakofler, K.; Barrett, E. Reducing non-contact electric arc injuries: An investigation of behavioral and organizational issues. J. Saf. Res. 2007, 38, 597-608.

99. Commonwealth of Pennsylvania. Mine Families First Resource Reference Manual; Commonwealth of Pennsylvania: Harrisburg, PA, USA, 2008.

100. Kowalski, K.; Podlesny, A. The Effects of Disaster on Workers: A Study of Burnout in Investigators of Serious Accidents and Fatalities in the US Mining Industry; National Institute for Occupational Safety and Health: Pittsburgh, PA, USA, 2000.

101. Vaught, C.; Mallett, L.; Kowalski, K.; Brnich, M. Workers response to realistic evacuation training. In Proceedings of the International Emergency Management Conference, Copenhagen, Denmark, 19-20 January 1997.

102. Moch, M.; Fitzgibbons, D. The relationship between absenteeism and production efficiency: An empirical assessment. J. Occup. Psychol. 1985, 58, 39-47.

103. Hu, T.; Slaysman, K. Health-related economic costs of the three-mile island accident. Soc. Econ. Plann. Sci. 1984, 18, 183-193.

104. Tucker, P.; Pfefferbaum, B.; Doughty, D.; Nixon, S. Body handlers after terrorism in Oklahoma City: Predictors of posttraumatic stress and other symptoms. Am. J. Orthopsychiatry 2002, 72, 469-475.

105. Galea, S.; Resnick, H. Psychological sequelae of the September 11 terrorist attacts in New York city. New Eng. J. Med. 2002, 346, 982-987.

106. Camm, T.; Girard-Dwyer, J. Economic consequences of mining injuries. In Proceedings of the Society of Mining Engineers Annual Conference, Denver, CO, USA, 22-25 February 2004.

107. Navarro, C.; Bass, C. Guidelines for managing employee absence. Benefit. Compensat. Digest 2006, 43, 32-34.

108. Yueng-Hsiang, H.; Leamon, T.; Courtney, T.; DeArmond, S.; Chen, P.; Blair, M. Financial decision makers' views on safety. Prof. Saf. 2009, 54, 36-42.

109. Ursano, R.; Fullerton, C.; Vance, K.; Kao, T. Posttraumatic stress disorder and identification in disaster workers. Am. J. Psychiatry 1999, 156, 353-359.

(C) 2012 by the authors; licensee MDPI, Basel, Switzerland. This article is an open access article distributed under the terms and conditions of the Creative Commons Attribution license (http://creativecommons.org/licenses/by/3.0/). 